\title{
Biodiversité et équilibre du régime alimentaire
}

Le cas des Ntomba de la forêt inondée (Cuvette centrale, République du Congo)

Biodiversity and the balance diet : the case of the Ntomba of the swamped forest (Central Basin, Congo Republic)

\section{Hélène Pagezy}

\section{(2) OpenEdition}

\section{Journals}

Édition électronique

URL : http://journals.openedition.org/ethnoecologie/1424

DOI : $10.4000 /$ ethnoecologie. 1424

ISSN : 2267-2419

Éditeur

Laboratoire Eco-anthropologie et Ethnobiologie

Référence électronique

Hélène Pagezy, "Biodiversité et équilibre du régime alimentaire », Revue d'ethnoécologie [En ligne],

3| 2013, mis en ligne le 12 novembre 2013, consulté le 19 avril 2019. URL : http://

journals.openedition.org/ethnoecologie/1424 ; DOI : 10.4000/ethnoecologie.1424

Ce document a été généré automatiquement le 19 avril 2019.

Revue d'ethnoécologie est mis à disposition selon les termes de la licence Creative Commons Attribution - Pas d'Utilisation Commerciale - Pas de Modification 4.0 International. 


\section{Biodiversité et équilibre du régime alimentaire}

Le cas des Ntomba de la forêt inondée (Cuvette centrale, République du Congo)

Biodiversity and the balance diet : the case of the Ntomba of the swamped forest (Central Basin, Congo Republic)

Hélène Pagezy

\section{NOTE DE L'ÉDITEUR}

Hélène Pagezy (2 août 1945 - 3 mars 2013) était anthropologue biologiste, directeur de recherche au CNRS, et spécialisée en anthropologie de l'alimentation. Elle a conduit des recherches de terrain très approfondies en Afrique centrale, en premier lieu en République démocratique du Congo, puis en République centrafricaine et au Cameroun. Elle a abordé d'une manière novatrice et exemplaire l'étude des régimes alimentaires, prenant en compte les aspects biologiques et quantitatifs ainsi que ceux liés à la dépense énergétique, mais également les aspects sociaux et culturels impliqués dans

l'alimentation. Son terrain dans la région du Lac Tumba en RDC l'a conduite à étudier les interrelations entre les agriculteurs Oto et les chasseurs-cueilleurs Twa, apportant ainsi des informations originales sur un groupe de Pygmées méconnu. Elle a aussi engagé des recherches durables sur les régimes alimentaires spécifiques des femmes enceintes et ceux du couple mère-enfant, recherche qu'elle poursuivit en RCA. Sur son terrain de RDC, elle a réalisé un film primé à plusieurs reprises "Wale Chantal », remarquable mise en scène de ce cycle de la femme primipare. Elle s'est également illustrée dans l'étude des sociétés de pêcheurs de forêt équatoriale au Cameroun puis en Guyane française.

S'impliquant dans la restitution des recherches scientifiques auprès d'un public large comme auprès des communautés enquêtées, elle a récemment dirigé un gros travail collectif de recueil de dessins d'enfants dans diverses régions du monde, illustrant leur vision de la nature, travail qui s'est concrétisé d'abord par une exposition au Musée de 
l'Homme (2007-2008) puis un livre collectif (Pagezy et al. 2010).

Hélène Pagezy avait spécialement préparé cette synthèse de son travail sur le régime alimentaire des Ntomba de RDC pour être publié dans la Revue d'ethnoécologie;

malheureusement elle n'a pas pu en relire la version définitive.

Référence :

Pagezy H., Carrière S. et Sabinot C., Ed., 2010 - Nature du monde. Dessins d'enfants. CTHS, Paris, $260 \mathrm{p}$.

\section{Introduction}

1 Toutes les espèces forestières ne sont pas comestibles. Celles qui sont potentiellement consommables ne sont pas toutes consommées; en outre, les espèces consommées ne le sont pas quotidiennement ni par tous. Le régime alimentaire est passé au crible de facteurs écologiques, culturels et sociaux au cours des multiples étapes menant de l'alimentation (façon de s'alimenter) - choix, production, préparation, partage des aliments - à la nutrition qui débute avec l'ingestion, suivie par la dégradation et finalement l'utilisation des nutriments. Une question importante que se posent les éco-anthropologues concerne les relations entre diversité biologique, régime alimentaire et état nutritionnel. Si une importante biodiversité est une condition nécessaire à la réalisation d'un régime alimentaire équilibré, est-elle pour autant une condition suffisante? En effet, l'équilibre du régime alimentaire doit être assuré, non seulement au cours des différentes saisons de l'année, mais aussi concerner les différentes catégories de la population (Pagezy 1988a).

2 J'appuierai mes propos sur l'étude de villages ntomba proches de Nzalekenga ${ }^{1}$, en République Démocratique du Congo. Ce village est situé sur une route d'importance secondaire menant de la mission protestante de Ntondo sur la rive sud-est du lac Tumba, à Mpangi, village ekonda en pleine forêt (Figure 1). 
Figure 1 : Carte de la zone de travail au sud-est du lac Tumba (RDC)

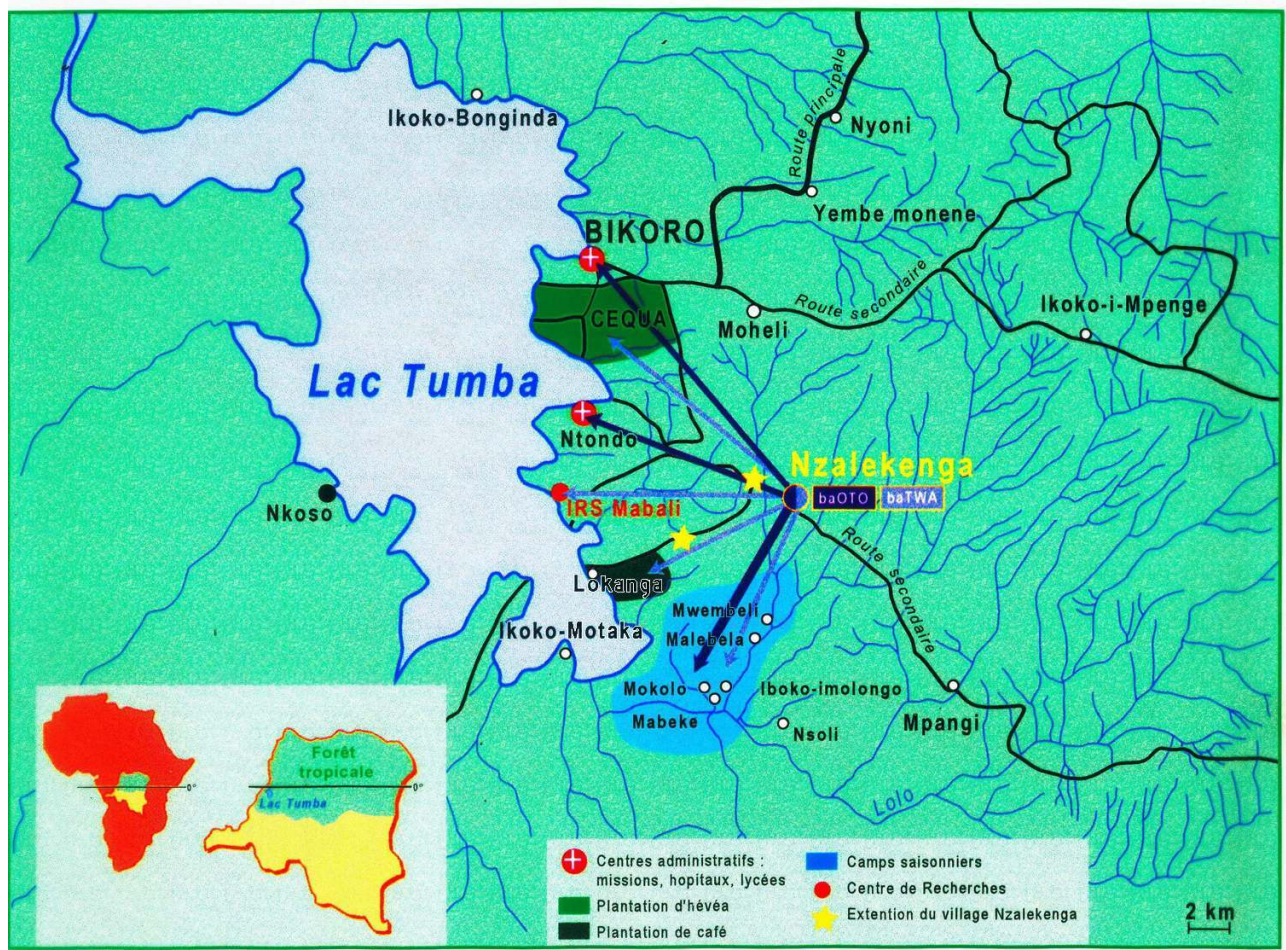

Photographie 1 : Vue du village de Nzalekenga

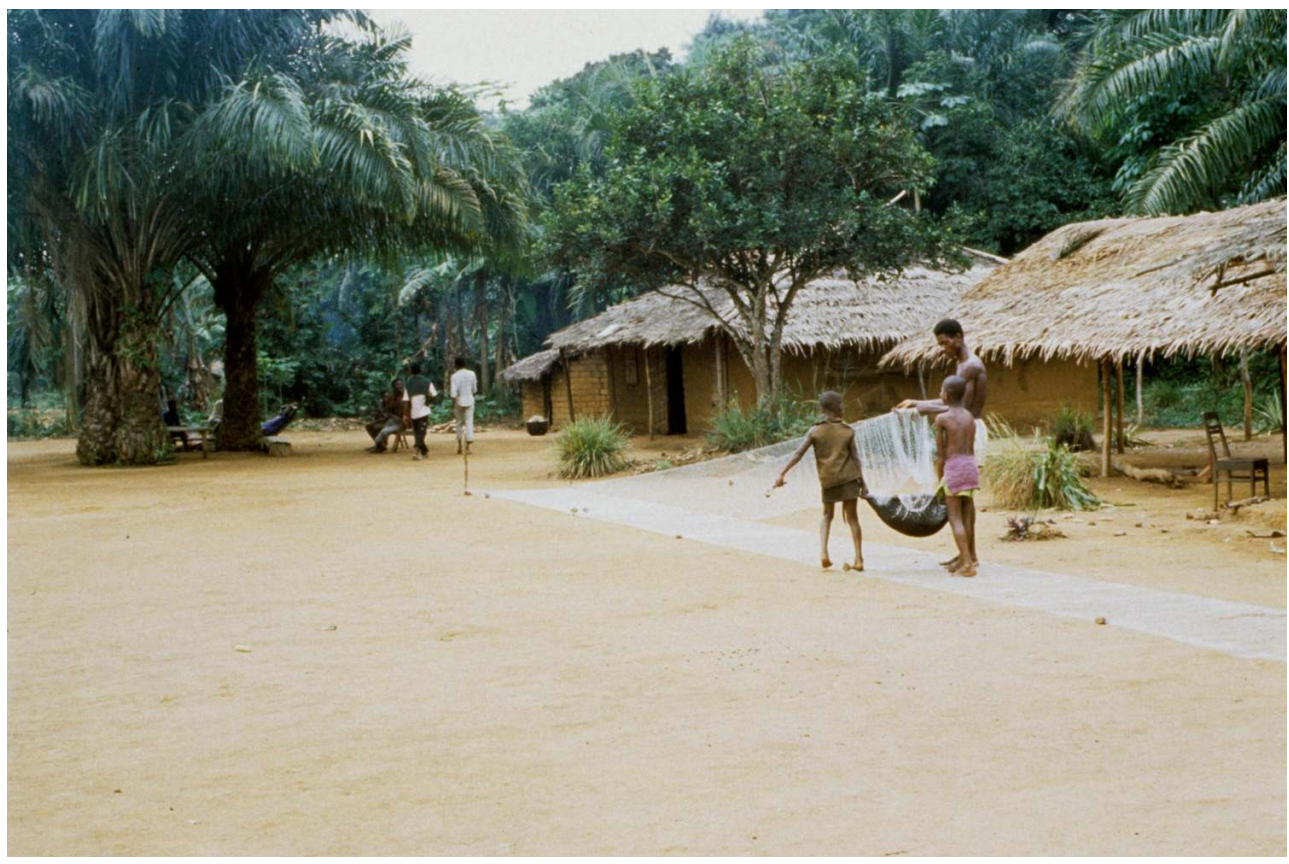

(c) H. Pagezy 


\section{Les milieux et les hommes dans la région du lac Tumba}

\section{Les biotopes de la forêt inondée}

Les Ntomba, sous-ethnie des Mongo du Sud ${ }^{2}$, occupent la forêt inondée ${ }^{3}$ de la Cuvette centrale (Aubréville 1949) à l'est et au sud du lac Tumba (Marlier 1958). Excepté les villages situés sur la route principale reliant les centres extra-coutumiers ${ }^{4}$ à la capitale de province, Mbandaka, l'ensemble de la région est enclavée. Les routes sont peu à très peu fréquentées et inégalement entretenues ${ }^{5}$. La principale caractéristique de la Cuvette centrale est son réseau hydrographique hypertrophié. L'espace est constitué d'une mosaïque d'écosystèmes décrits par Bouillenne et al. (1955). Il s'agit de (1) ngonda, la forêt de haute futaie, (2) e.bale, le lac proprement dit, (3) me.longo ${ }^{6}$, les rivières qui s'y jettent et leurs affluents, (4) li.amba, la forêt inondée, (5) mo.konda, la forêt de terre ferme occupée par les villages et les plantations, enfin (6) les bi.sobe savanes acides naturelles. Dans certains de ces milieux résident des génies, les bi.lima, chargés des relations entre les hommes et la faune sauvage. Les femmes-sirènes règnent sur les milieux aquatiques; elles créent les poissons qu'elles donnent aux pêcheurs, tandis que sur la terre ferme, mariés à celles-ci ou célibataires, les hommes-génies créent le gibier et le donnent aux chasseurs (Pagezy 2006a).

Si le niveau du lac suit une saisonnalité bimodale - deux saisons de basses eaux alternent avec deux saisons de hautes eaux - les régimes des rivières et celui de la forêt marécageuse suivent également des variations d'étiage avec un certain décalage, dû à l'apport des pluies locales (Figure 2).

Figure 2 : Niveau du lac et régime des pluies

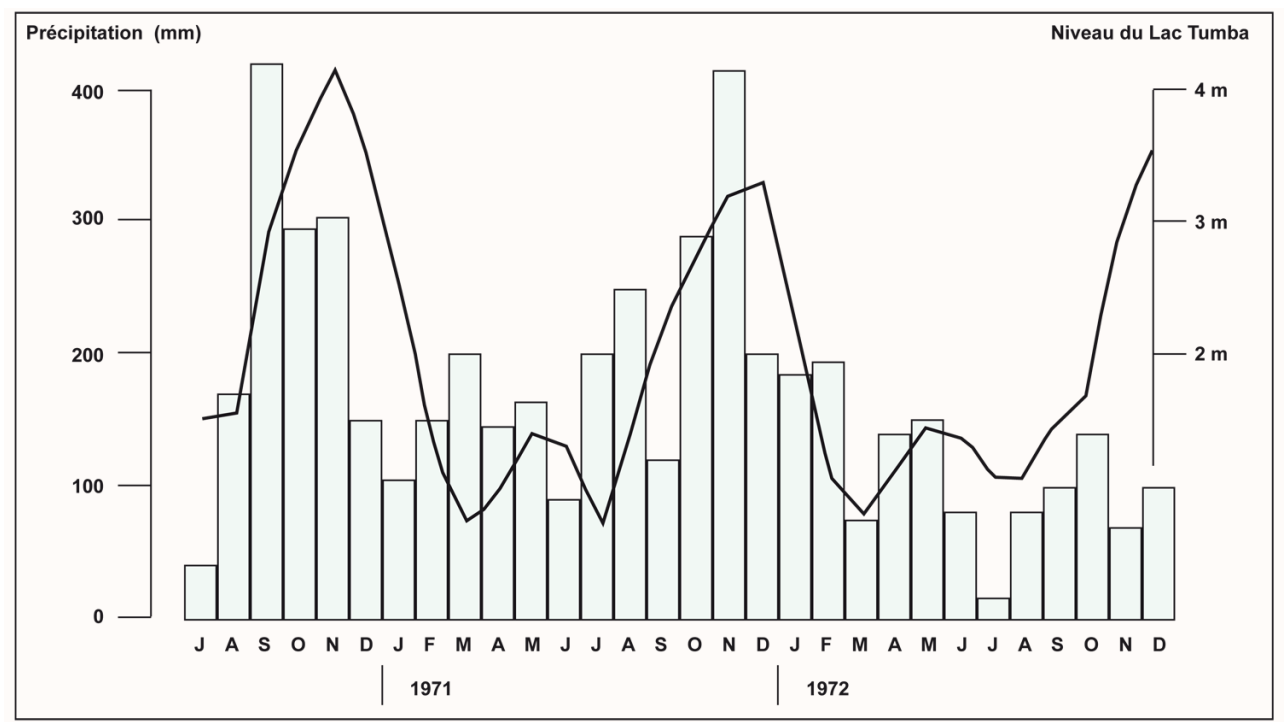

\section{Deux castes d'une même ethnie}

Les habitants des rives du lac sont descendants de pêcheurs en eau profonde, les Elenga, venus du fleuve Congo et de son affluent l'Oubangui par le chenal d'Irebu. Ce n'est pas le 
cas des baOto et des baTwa de la forêt. Les baOto ${ }^{7}$ sont des agriculteurs sur brûlis, chasseurs et pêcheurs de rivière et de forêt inondée; les baTwa, sont descendants de chasseurs collecteurs; ils cultivent pour le compte des baOto et ne pratiquent pas la pêche en eau profonde. Ils les ont accompagné dans leur quête de nouvelles terres, leur ont servi de guides et d'éclaireurs, assurant leur protection lors de conflits avec les populations autochtones. Jusqu'à la période coloniale, baOto et baTwa se déplaçaient à l'intérieur du domaine foncier du clan, légitimé par le droit du premier occupant (Müller 1958). C'est pour ces raisons historiques que l'on ne trouve pas de baTwa sur les rives du lac Tumba, bien que certaines familles se soient récemment installées dans les missions et les plantations pour y travailler. Le semi-nomadisme des populations de forêt s'est transformé au début $\mathrm{du} \mathrm{xx}^{\mathrm{e}}$ siècle en sédentarisation forcée le long des routes, afin de faciliter les travaux imposés par le colonisateur: récolte du copal et du caoutchouc sauvage, entretien des routes, et versement de l'impôt (Jewsiewicki 1979, Hulstaert 1961).

6 La proximité de la langue et de la culture immatérielle des baOto et des baTwa peut s'expliquer par leur longue histoire commune. Leurs relations sociales s'apparentent à celles de vassaux (baTwa) aux suzerains (baOto), de sorte que certains auteurs, tel que Müller (1964) ont avancé le terme de « castes " pour les désigner. En effet, entre baOto et baTwa, les relations sexuelles sont strictement prohibées, bien qu'il existe comme dans toute société, des espaces de tolérance. Attirantes mais intouchables, les femmes twa, dans le secret de la forêt, ne ratent pas une occasion d'aguicher les hommes oto afin de les séduire. Chez ces derniers, l'adultère n'est puni que s'il est pris en flagrant délit. Si le séducteur est de même caste, il est poursuivi dans la forêt par le mari trompé, machette à la main. Sa femme retourne dans sa propre famille jusqu'à ce que réparation s'ensuive. Si l'adultère est commis avec une femme twa, la punition devient bannissement. Le fautif devient la honte de sa famille et la risée de tous. Il sera condamné au célibat ; aucune femme de sa caste ne daignera l'épouser. Une solution : l'exil en milieu extra-coutumier (plantations, ville), loin de la réprobation sociale. S'il reste au village, méprisé de tous, il devient à vie à la charge de sa propre famille (Pagezy 1988a).

\section{Les disponibilités alimentaires dans la région du lac Tumba}

\section{Méthodologie}

7 Afin de faire émerger l'importance de la biodiversité alimentaire sauvage, j'ai confronté plusieurs sources d'information. Durant mes 60 mois de terrain, j'ai recensé les plantes et animaux comestibles en recoupant la liste obtenue par entretiens avec des observations, des photos, des descriptions, des noms vernaculaires, des récoltes de spécimens (herbiers, conservation dans alcool, peaux et recueil de crânes) ${ }^{8}$ et par leur présence dans les enquêtes familiales de consommation (Pagezy 2004), menées entre 1970 et 1972.9 (Photo 2) 
Photographie 2 : La pesée

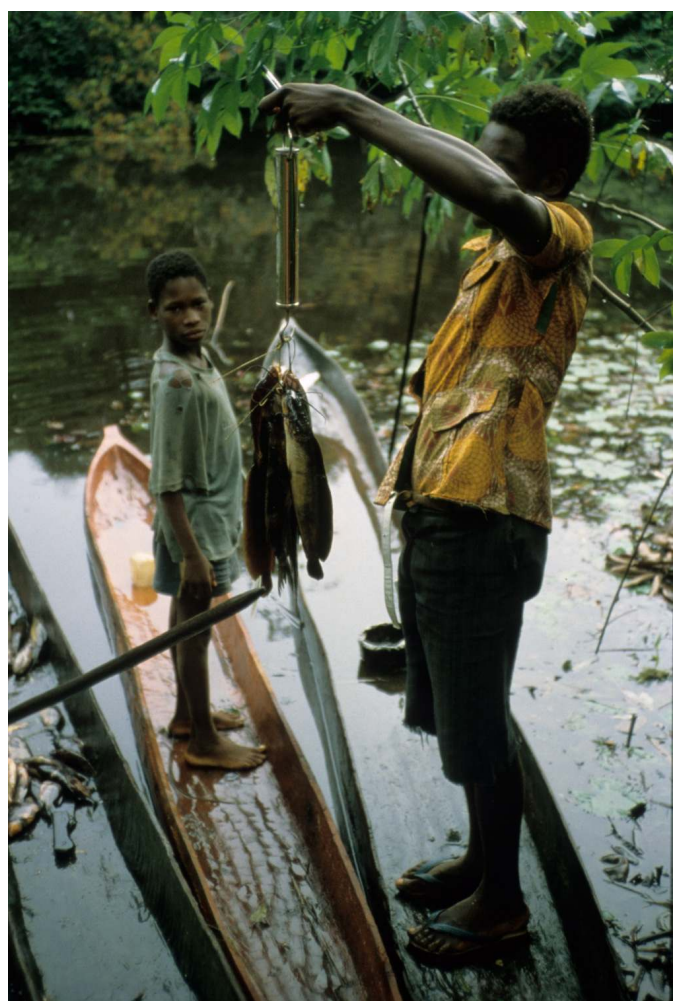

L'enquête d'anthropologie de l'alimentation nécessite des mesures des prises et de la consommation (c) H. Pagezy

\section{Des espèces consommables aux espèces consommées}

8 J'ai dénombré 267 espèces sauvages - 80 espèces végétales et 187 espèces animales - citées comme consommables par les Ntomba (Tableau 1). 
Tableau 1 : Approche de la biodiversité alimentaire dans la région du lac Tumba

\begin{tabular}{|c|c|c|c|}
\hline \multirow{5}{*}{ Végétaux sauvages : 80 espèces } & Oto + Twa & spèces & Commentaires \\
\hline & Féculents & $T=6$ & $\begin{array}{l}5 \text { ignames dont } 2 \text { consommés par les baTwa } \\
1 \text { colocase }\end{array}$ \\
\hline & Champignons & $T=26$ & dont 11 rares \\
\hline & Fruits et graines & $T=28$ & dont 3 réservés aux enfants * \\
\hline & Feuilles et tiges & $T=20$ & dont 3 jeunes pousses et 6 consommés par les seuls ba Twa \\
\hline \multirow[t]{5}{*}{ Animaux sauvages : 187 espèces } & Oto + Twa & spèces & Commentaires \\
\hline & $\begin{array}{l}\text { Hyménoptères } \\
\text { Chenilles (mèto) } \\
\text { Guêpes maçonnes (imago) }\end{array}$ & $\begin{array}{r}T=33 \\
31 \\
2\end{array}$ & $\begin{array}{l}\text { dont } 1 \text { chrysalide et } 12 \text { consommées par les seuls baTwa. } \\
\text { Signalons le miel mpako produit par les abeilles nzue qui } \\
\text { apparaît dans le régime de sevrage des baTwa }\end{array}$ \\
\hline & Termites (ndonge), reine et imagos & $T=2$ & $\begin{array}{l}\text { Réservées aux femmes et enfants twa; ; Actuellement les hommes } \\
\text { oto peuvent en consommer, excepté l'espèce des marais. }\end{array}$ \\
\hline & $\begin{array}{l}\text { Autres insectes } \\
\text { Coléoptères (llarves et imagos) } \\
\text { Orthoptères }\end{array}$ & $\begin{array}{r}T=3 \\
2 \\
1\end{array}$ & $\begin{array}{l}2 \text { larves de palmier réservées aux femmes et aux enfants; } 2 \\
\text { imagos réservés aux enfants twa. } \\
1 \text { imago de sauterelle verte consommé par les enfants twa }\end{array}$ \\
\hline & Crustacés & $T=3$ & 2 crevettes et 1 crabe d'eau douce consommés par les baOto \\
\hline \multirow{9}{*}{ Vertébrés : $T$ = 146} & $\begin{array}{l}\text { Poissons } \\
\text { Lac, Rivières, Forêt inondée et Marais }\end{array}$ & $T=54$ & \\
\hline & Reptiles & $T=19$ & 12 serpents, 3 tortues, 3 crocodiles, 1 varan \\
\hline & Oiseaux & $T=20$ & Rarement consommés; peu appréciés \\
\hline & Mammifères & $T=53$ & \\
\hline & Grimpeurs & 15 & Écureuils, singes, prosimiens \\
\hline & Terrestres à griffes & 22 & $\begin{array}{l}4 \text { mangoustes, } 9 \text { tachetés, } 3 \text { rats et musaraigne, } 4 \text { pangolins } \\
\text { et porcs épics }\end{array}$ \\
\hline & Terrestres à sabots & 9 & 8 antilopes, 1 potamochère \\
\hline & Aquatiques & 3 & Loutres, potamogale \\
\hline & Volants & 4 & Anomalures et chauves souris \\
\hline
\end{tabular}

Nombre d'espèces sauvages végétales et animales consommées par les Ntomba de janvier 1971 à juin 1972

$9 \quad$ Au Tableau 2 figurent les principaux aliments issus de l'agriculture et de l'élevage. Leur importance numérique, incomparablement plus faible, inclut les aliments de base manioc ou banane plantain - qui sont cultivés. Selon l'enquête de consommation alimentaire de 1971-72, entre un quart et un tiers des espèces animales sauvages citées ont été réellement consommées, soit $26 \%$ des reptiles ( 5 espèces sur 19$)$ et $36 \%$ des mammifères répertoriés (19 espèces sur 53). En ce qui concerne les poissons, $53 \%$ des espèces de la forêt inondée ont été consommées (10 espèces sur 19) et $25 \%$ des espèces du lac et des rivières (8 espèces sur 32$)$. 
Photographie 3 : Le retour des champs

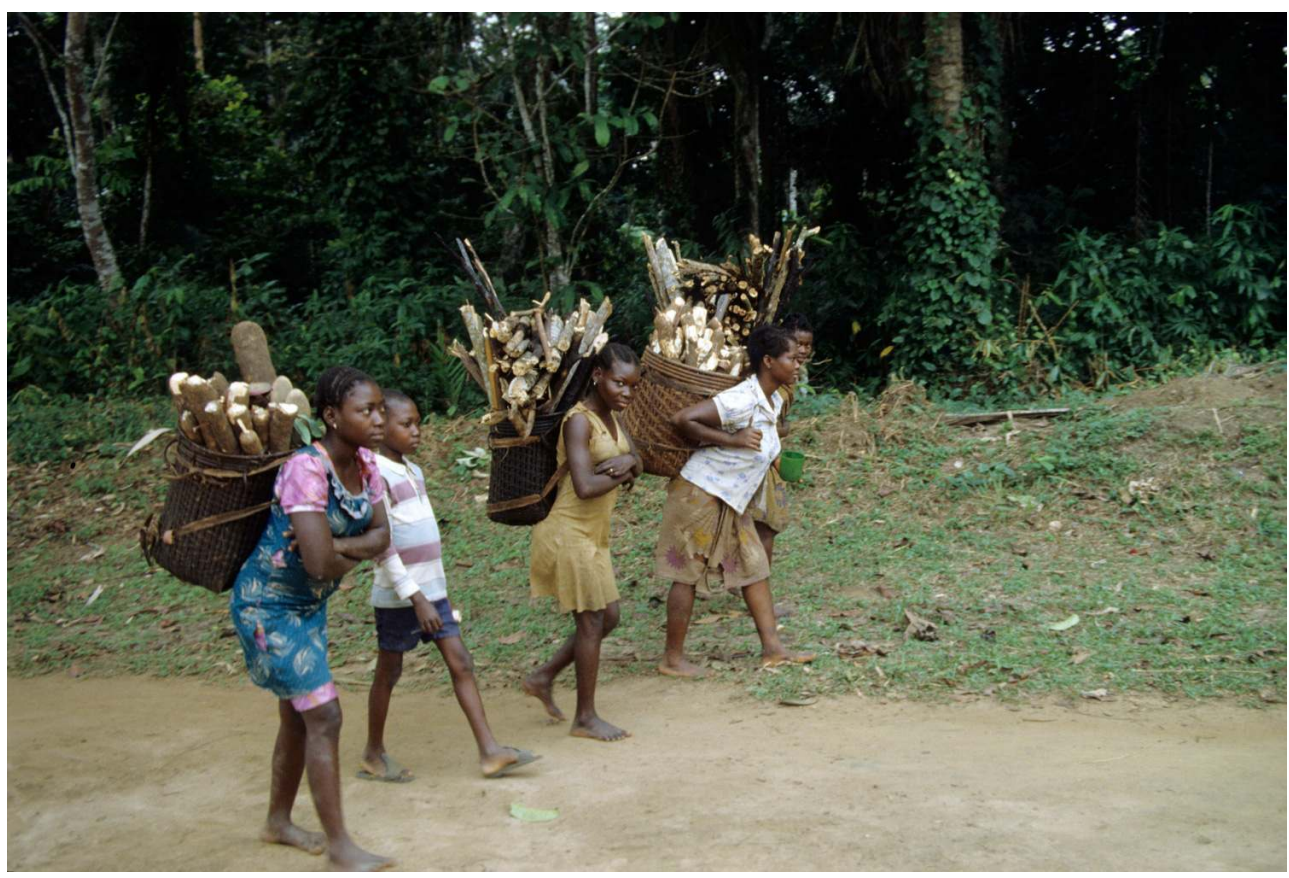

Les jeunes filles sont lourdement chargées de tubercules de manioc et de bois de feu (c) H. Pagezy

Photographie 4 : Préparation de la pâte de manioc

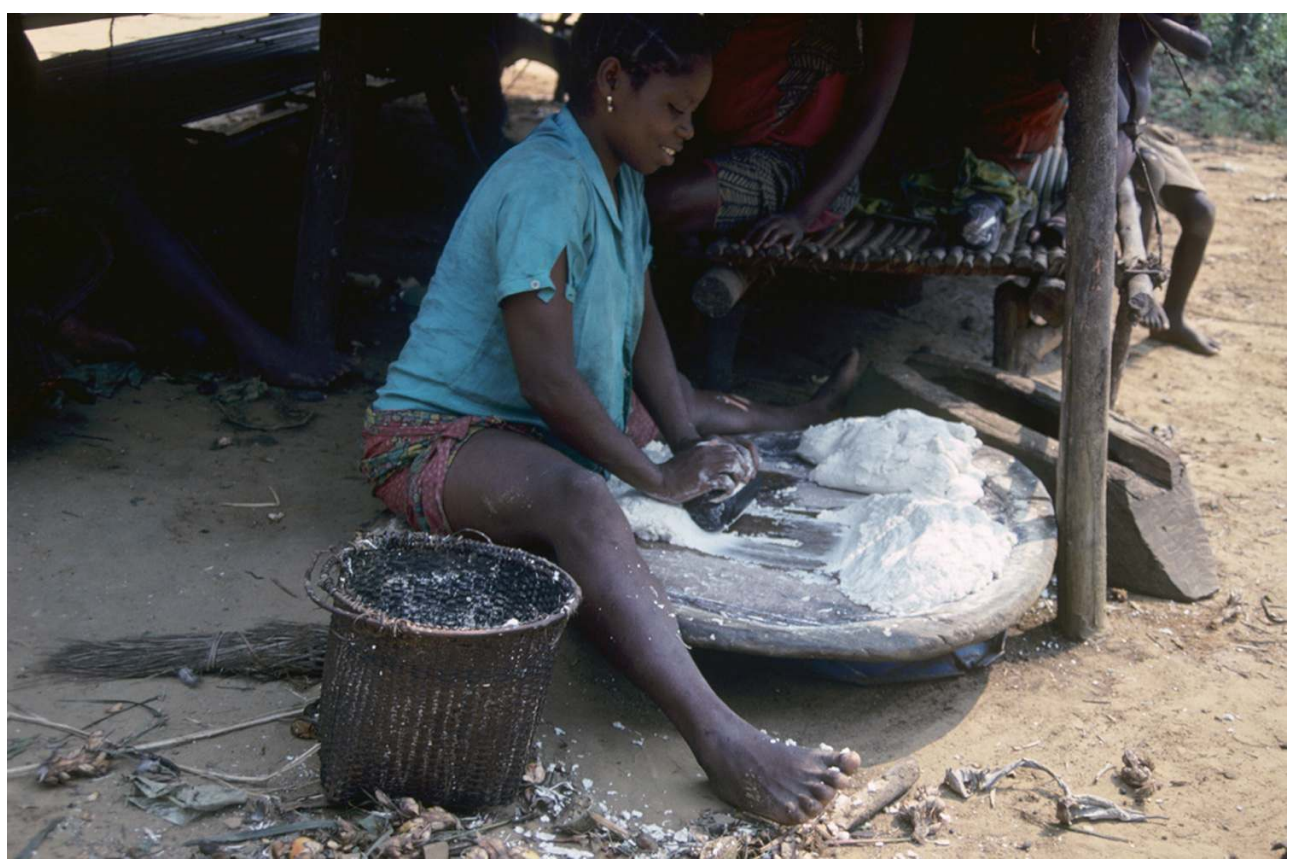

Après rouissage, les tubercules épluchés sont écrasés sur un plateau de bois (c) H. Pagezy 
Photographie 5 : Préparation de la pâte de manioc

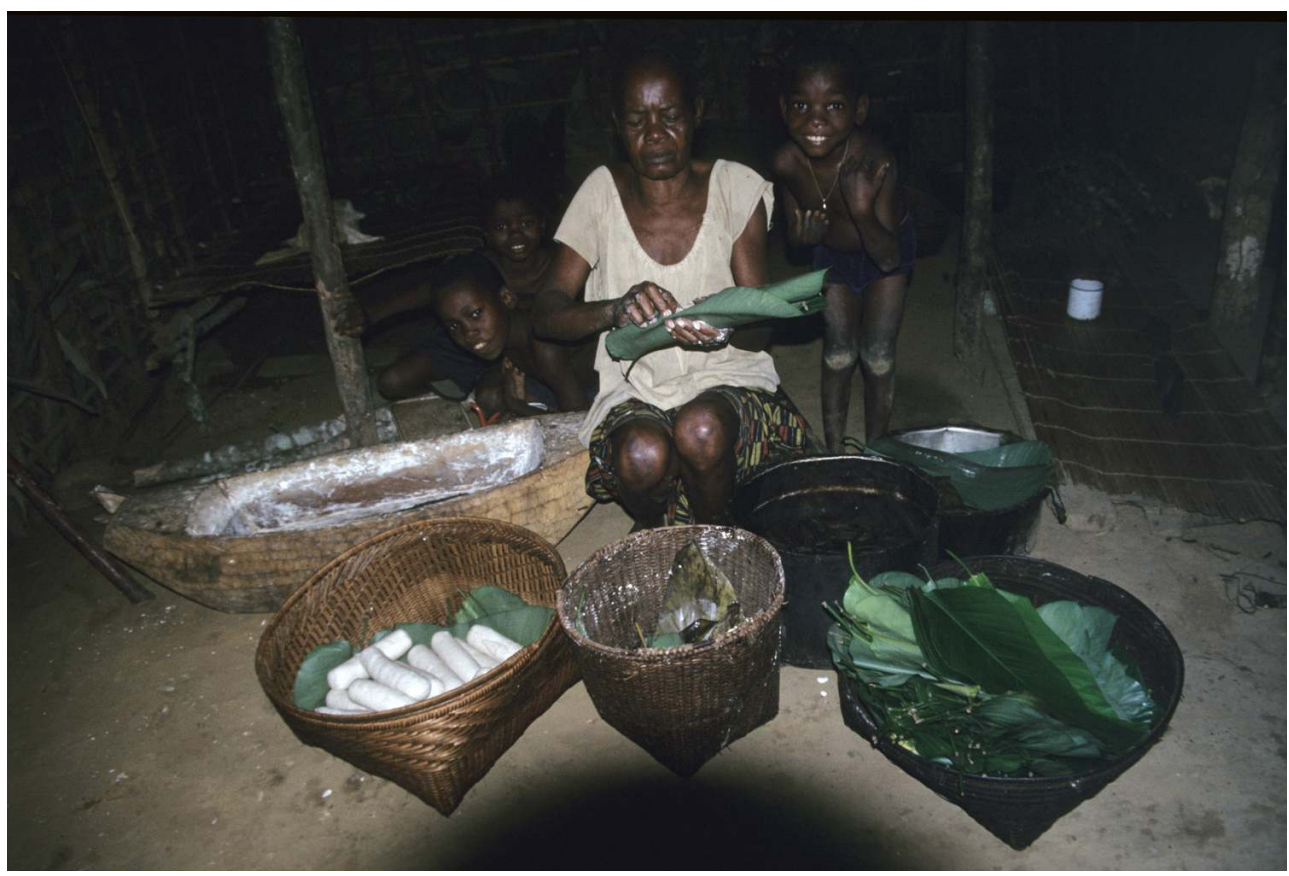

La pâte de manioc bien lisse et façonnée en boudins, est emballée dans des feuilles de marantacées, avant d'être cuites à l'étouffée

(c) H. Pagezy

Tableau 2 : Approche de la biodiversité alimentaire dans la région du lac Tumba

\begin{tabular}{|c|c|c|c|}
\hline \multirow{4}{*}{ Végétaux cultivés : 47 espèces } & Oto + Twa & n. espèces & Commentaires \\
\hline & Féculents & 7 & $\begin{array}{l}\text { Manioc doux et amer et leurs variétés, bananes plantain, patate douce, } \\
3 \text { espèces d'ignames. }\end{array}$ \\
\hline & Fruits et graines & 29 & 17 espèces consommées crues, 12 cuites \\
\hline & Feuilles et tiges & 11 & \\
\hline Animaux d'élevage: 6 espèces & & & $\begin{array}{l}3 \text { fréquents: poule, canard, chèvre } \\
3 \text { rares: mouton, porc, vache (provenant de la mission ou de le la } \\
\text { plantation CEQUA). Consommés à Noël. }\end{array}$ \\
\hline
\end{tabular}

Nombre d'espèces végétales et animales issues de l'agriculture et de l'élevage consommées par les Ntomba de janvier 1971 à juin 72 
Photographie 6 : Les feuilles de manioc sont équeutées avant d'être préparées

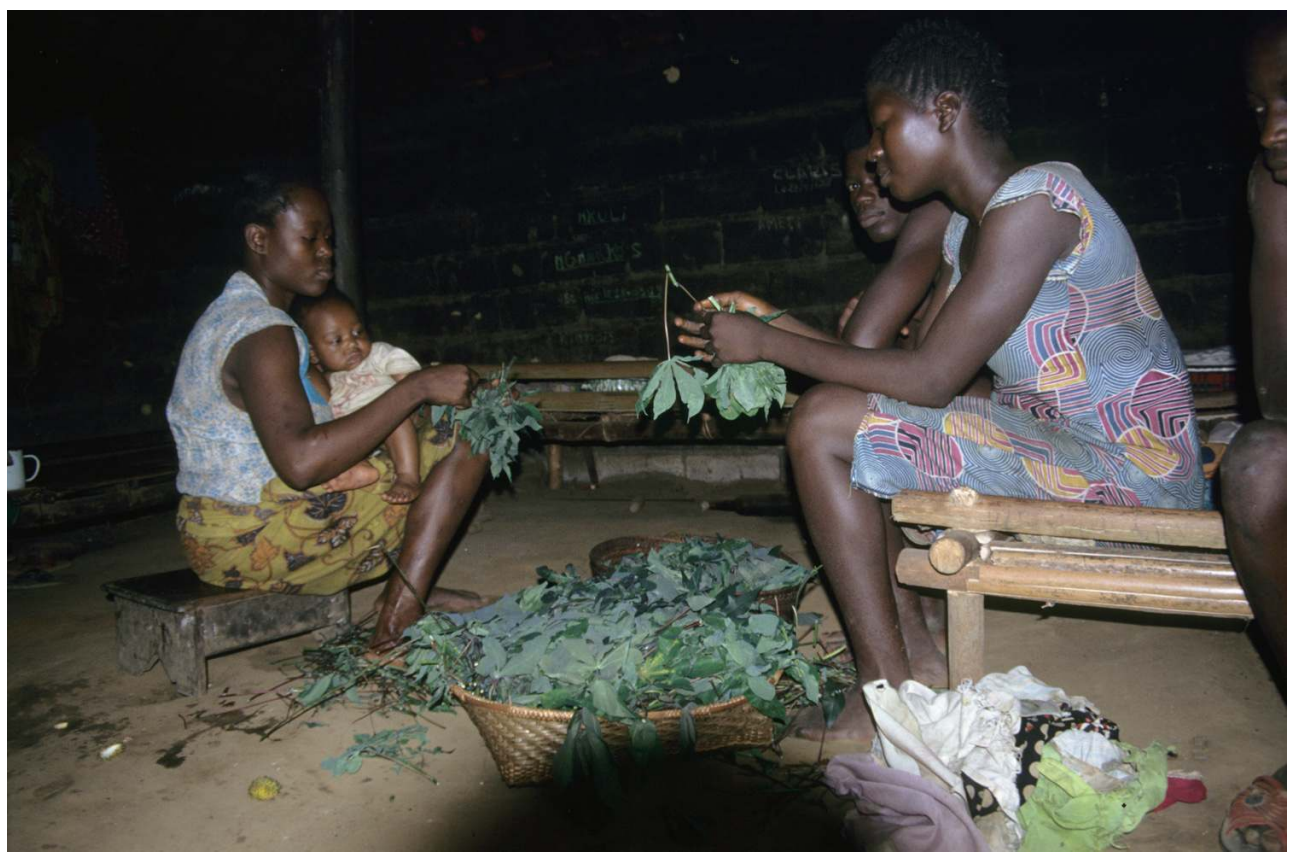

(c) H. Pagezy

Photographie 7 : Après avoir été blanchies, les feuilles de manioc sont réduites en purée dans un plateau de bois à rainures

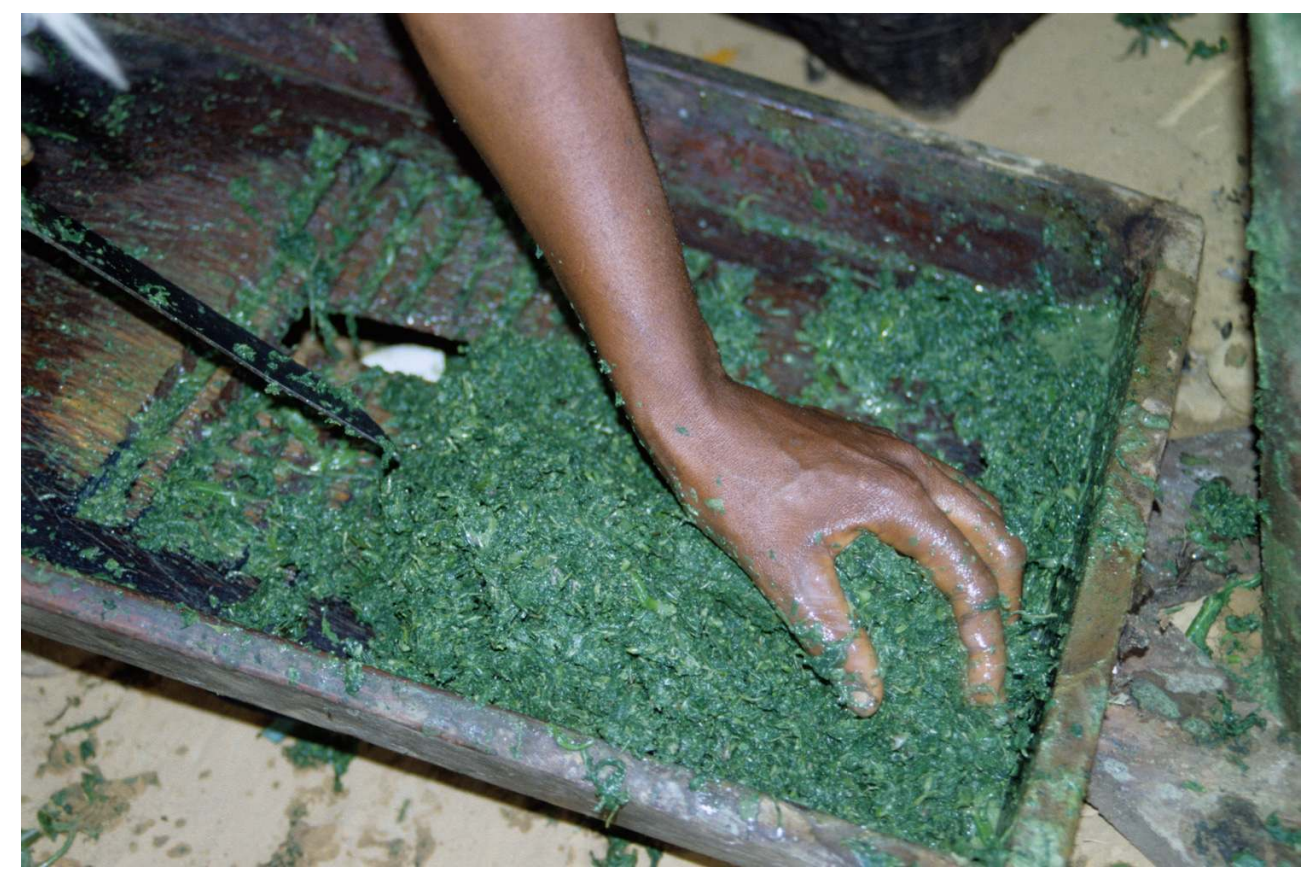

(c) H. Pagezy

10 D'une façon générale, les baTwa se distinguent des baOto par un choix plus large d'espèces sauvages, délaissées par ces derniers, sortes de marqueurs identitaires (Tableau 3). Aussi, ils apparaissent comme les gardiens d'une culture passée qui leur était probablement commune. 
Tableau 3 : Fréquence de consommation de feuillages chez les baOto et les baTwa

\begin{tabular}{|c|c|c|}
\hline Janvier 1971 - mai 1972 (17 mois d'enquête) & baOto & baTwa \\
\hline $\mathrm{N}$ jours d'enquête & 3171 & 3439 \\
\hline $\mathrm{N} 1$ jours de consommation feuilles sauvages et cultivées & 704 & 419 \\
Fréquence (N1/N) & $22,2 \%$ & $12,2 \%$ \\
\hline N2 jours de consommation feuilles cultivées & 574 & $37,0 \%$ \\
\hline Fréquence (N2/N1) & $81,5 \%$ & 264 \\
\hline N3 jours de consommation feuilles sauvages & 130 & $63,0 \%$ \\
Fréquence (N3/N1) & $18,4 \%$ & \\
\hline
\end{tabular}

Pourcentage d'espèces cultivées (C) par rapport aux sauvages (S). Enquête de consommation (1971-1972)

\section{Le régime des Ntomba et les stratégies alimentaires}

\section{Normes en matière d'alimentation}

11 Chez les Ntomba, kolè (kolia en lingala) signifie manger, et est à la fois un aliment de base qui remplit le ventre, accompagné de nourriture animale. Les normes en matière d'alimentation font essentiellement référence au repas du soir qui rassemble les membres d'un même foyer. Il comporte obligatoirement l'aliment de base, source de glucides et d'énergie mais pauvre en protéines végétales carencées; les tubercules de manioc ou autres féculents sont remplacés au bord du lac par les bananes plantains. Le manioc est accompagné d'espèces animales terrestres - gibier, chenilles - ou aquatiques - poisson, crevettes - riches en protéines de haute valeur biologique, en graisse et en vitamines liposolubles. Ces «viandes » sont servies avec des feuilles sauvages ou cultivées dont les plus communes sont les feuilles de manioc. Ces feuillages sont riches en fibres, en vitamines hydrosolubles et en minéraux. Les plats sont préparés (ko.lamba) en sauce - la mo.saka, pulpe de noix de palme - ou à l'huile de palme. Hautement énergétique, cette sauce, riche en lipides et en vitamines liposolubles, est parfois remplacée par une sauce aqueuse dans laquelle surnagent quelques condiments, tomates et piments. Le repas du soir est équilibré dans la mesure où il contient les principales catégories de nutriments nécessaires aux fonctions vitales. Le matin, avant de partir au travail, sont finis les restes de la veille dont une partie servira de coupe-faim dans la matinée. Les fruits et graines, riches en vitamines et en minéraux, sont consommés au cours de la journée, de façon opportune dans la forêt, ou de retour au village. C'est encore de retour au village que sont pris les coupe-faim - noix de palme, manioc doux, arachides, maïs - cuits directement dans les braises (préparation rapide ko.tumba), poisson fretin ou chenilles emballées dans des feuilles (façon ko.tumba i.boke). 
Photographie 8 : Deux enfants pilent des noix de palme cuites, pour en extraire l'huile

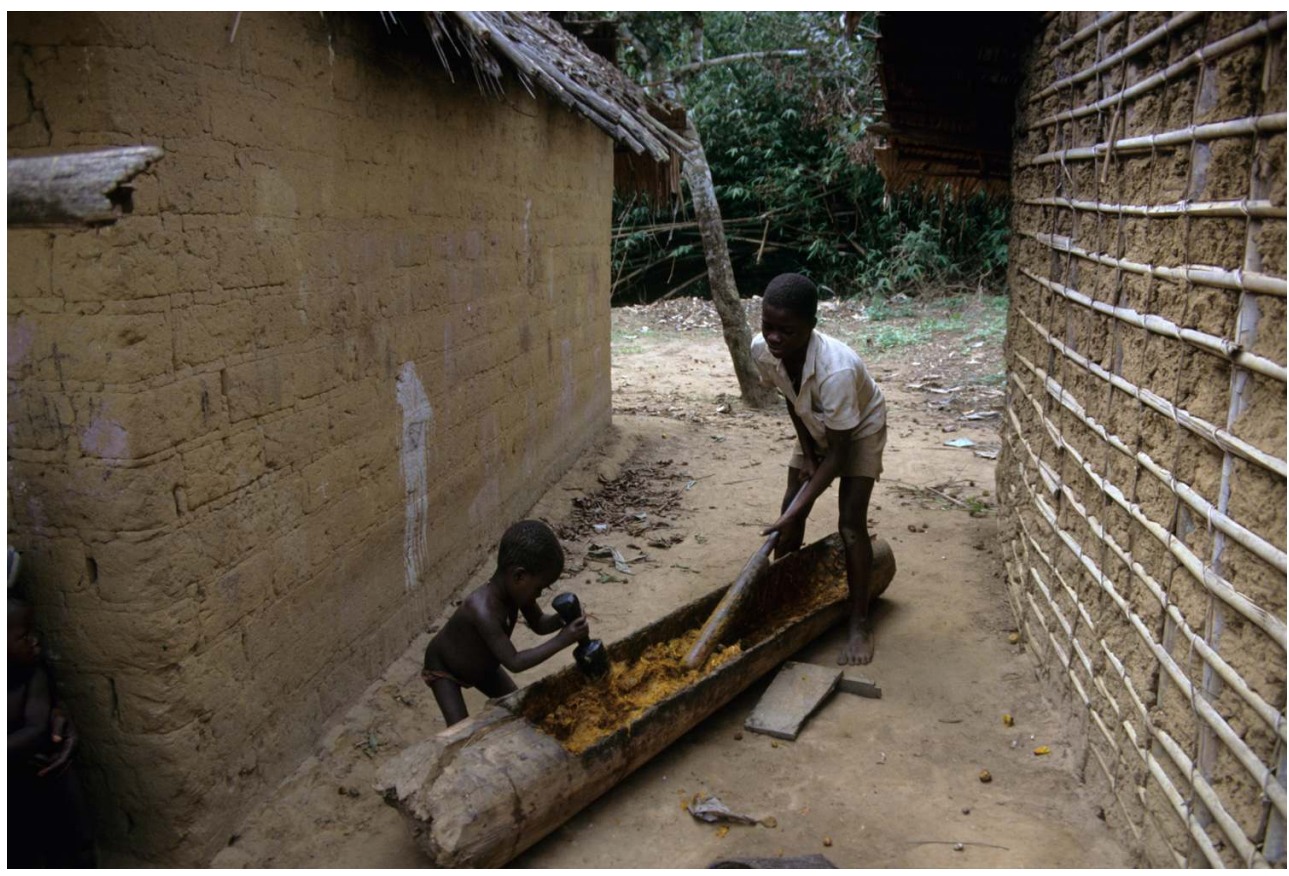

(C) H. Pagezy

12 Pendant la saison des pluies, le manque de nourriture animale génère de nombreuses plaintes chez petits et grands. Naoka nzala, "je ressens la faim; c'est la famine», gémissent des journées entières enfants comme adultes, bien qu'ils fassent tous les jours leur plein d'énergie. Ce manque spécifique d'aliments carnés pendant la saison des pluies est la cause d'un stress à la fois nutritionnel et psychoculturel, connu des ethnologues sous le nom de « faim saisonnière » ou « faim de viande ». Non exclusif de la forêt humide, ce syndrome a été décrit dans diverses régions du monde, tropicales et même arctiques (Miracle 1961, Ogbu 1973, Nurse 1975, Heywood \& Nurse 1980, Garine \& Pagezy 1989, B. Robbe communication personnelle pour les Inuit). Dans la Cuvette centrale, ce stress bisannuel ne dure que deux semaines; il est plus intense et est associé à une forte carence énergétique dans d'autres régions comme le Sahel où on parle de disette.

D'après les résultats des enquêtes de consommation, baOto et baTwa ont un régime alimentaire qualitativement très proche, résultant d'espèces issues des mêmes milieux (Tableau 4). Ils diffèrent davantage dans leur aspect quantitatif, en relation avec les stratégies propres à chaque caste, à chaque saison et en fonction des milieux (Pagezy 1992). Enfin, une minime proportion du régime alimentaire des Ntomba provient - au début des années 70 - de denrées importées. Celles-ci sont achetées au détail à des revendeurs itinérants, ou dans des échoppes tenues par un gérant et alimentées par la tournée bimensuelle d'un commerçant de Mbandaka ${ }^{8}$. 
Tableau 4 : Profils calorique et protéique du régime alimentaire ntomba en 1971-1972

\begin{tabular}{|c|c|c|c|c||c|c|c|}
\cline { 2 - 8 } \multicolumn{1}{c|}{} & \multicolumn{3}{c|}{$\%$} & \multicolumn{3}{c|}{$\%$ protéines } \\
\cline { 2 - 8 } \multicolumn{1}{c|}{} & Groupement & Ressources nat. & Agric. Élevage & Importation & Ressources nat. & Agric. Élevage & Importation \\
\hline $\begin{array}{c}\text { Février 1971 - Juin } 1972 \\
\text { Bonsende (route) }\end{array}$ & Oto & $7,3 \%$ & $90,6 \%$ & $1,8 \%$ & $49,8 \%$ & $49,1 \%$ & $1,7 \%$ \\
\cline { 2 - 8 } & Twa & $6,6 \%$ & $92,8 \%$ & $0,4 \%$ & $49,0 \%$ & $53,4 \%$ & $0,5 \%$ \\
\hline \hline $\begin{array}{c}\text { Mai 1971 - Juin 1972 } \\
\text { Besongo I (forêt) }\end{array}$ & Oto & $9,6 \%$ & $88,0 \%$ & $2,0 \%$ & $58,4 \%$ & $40,4 \%$ & $0,9 \%$ \\
\cline { 2 - 8 } & Twa & $8,2 \%$ & $91,6 \%$ & $0,1 \%$ & 48,3 & $51,5 \%$ & $\operatorname{tr}$ \\
\hline \hline $\begin{array}{c}\text { Avril 1971- Juin 1972 } \\
\text { Besongo II (Lac) }\end{array}$ & Oto & $17,9 \%$ & $80,2 \%$ & $1,6 \%$ & $81,1 \%$ & $18,2 \%$ & $0,6 \%$ \\
\hline
\end{tabular}

ROUTE : VILLAgES OTO ET TWA DE LA ROUTE PRINCIPALE (BIKORO-MBANDAKA) AU NORD-EST DU LAC ; FORÊT : VILLAgES OTO ET TWA DE FORÊT SUR PISTE SECONDAIRE DE L'EST DU LAC (MPAHA-MPANgI) ; LAC : VILLAgES OTO RIVERAINS DU SUD-EST DU LAC (PAS DE BATWA); RESSOURCES NAT. : RESSOURCES NATURELLES, PRESQU'EXCLUSIVEMENT ANIMALES ; AgRIC. ÉLEVAge : AgRICULTURE ET ÉLEVAgE ; IMPORTATION : DENRÉES D'IMPORTATION

\section{Variations saisonnières des aliments}

BaOto et baTwa se différencient en pratiquant, à des degrés divers, les mêmes activités de subsistance, sans toutefois mettre en jeu les mêmes pratiques. Les savoirs, savoir-faire, dispositifs techno-économiques et stratégies de production sont transmis entre générations, et parfois entre castes si aucun frein culturel ne s'y oppose. La priorité donnée à l'une ou l'autre activité, la fabrication et l'utilisation d'outils particuliers, sont des marqueurs de leur identité respective. Aussi, contrairement aux produits issus de l'agriculture et de l'élevage qui sont peu saisonniers, les ressources sauvages de la forêt et du milieu aquatique, sont hautement saisonnières (Pagezy 1988b). Selon l'enquête de consommation, en saison des pluies les Ntomba de forêt préparent un produit animal tous les deux ou trois jours, et jusqu'à 1,30 par jour en saison sèche (Pagezy 1996). Quant aux habitants du lac, leur régime alimentaire ne présentant pas de soudure, ils sont épargnés par la faim saisonnière. Il s'ensuit que les saisons de basses eaux sont vécues comme des périodes d'abondance, tandis que les saisons pluvieuses le sont comme des périodes de disette, dues au manque de nourriture animale (Pagezy 2004).

La périodicité de certaines ressources animales est parfois liée à des facteurs endogènes ; c'est le cas des chenilles, accessibles à la fin des saisons sèches, lorsqu'elles descendent, espèce après espèce, de leur arbre nourricier pour se nymphoser; ou encore des termites au moment de leur vol nuptial. Très abondantes certaines années, plusieurs espèces peuvent ne pas apparaître d'autres années. Parfois encore, une petite saison supplémentaire peut survenir de façon aléatoire en novembre-décembre (Pagezy 1988b, Pagezy 2004).

\section{Activités de production et échanges différés}

16 Si les baOto et baTwa ont des régimes alimentaires très proches, c'est grâce aux usages complémentaires des mêmes biotopes, associés à des techniques adaptées aux conditions écologiques et aux saisons (Pagezy 1985a). Les excédents font l'objet d'échanges différés ou de vente. 


\section{Partage de l'espace et des activités de subsistance entre baOto et baTwa}

17 La situation écologique des villages détermine l'accès aux ressources des terroirs. Forêt dense de terre ferme, rives du lac, campements de rivière, forêt marécageuse abritent les espèces caractéristiques de chaque biotope. Ainsi, au bord du lac, les villages n'ont pas accès aux mêmes ressources que ceux de forêt inondée, proches ou non de territoires de chasse $^{9}$. Aussi, une spécialisation se manifeste non seulement entre les castes, mais également entre familles au sein de chaque caste, en relation avec des choix qui leur sont propres et qui seront transmis (Pagezy 1985).

La forêt de terre ferme représente une opportunité pour installer un nouveau village, de nouvelles plantations ou de nouveaux quartiers, suite à la pression démographique ou l'appauvrissement des terres. Selon la tradition orale (Elshout 1963) remontant à quelques centaines d'années, les baTwa auraient accompagné les baOto dans leur migration vers l'ouest. Ils leur auraient servi d'éclaireurs dans la prospection de nouvelles terres, puis se seraient déplacés sur le territoire de clan de leurs suzerains (Müller 1958). La période coloniale ayant obligé les deux groupes à s'installer le long des routes pour un contrôle plus aisé des travaux imposés - récolte du caoutchouc sauvage, entretien des routes, paiement de l'impôt - baOto et baTwa s'y sont déplacés, créant des villages formés de la succession de quartiers - clans (bi.tuka) où les quartiers twa jouxtent ceux de leurs suzerains.

Les baOto sont des agriculteurs sur brûlis, pratiquant une courte jachère de 3 à 6 ans actuellement, contre plus de 10 ans autrefois. De 1971 à 1989, à Nzalekenga, le nombre moyen de plantations de manioc par famille est passé de 1,52 (0 à 4 ) à 2,50 (0 à plus de 5) chez les baOto ${ }^{10}$, et de 0,93 ( 0 à 2 ) à 1,18 ( 0 à 4) chez les baTwa avec des superficies deux fois moindres. Par ailleurs, les familles oto comme twa entretiennent un petit jardin de case et un petit élevage - quelques poules et chèvres - réservé aux occasions particulières. Bien que connaissant parfaitement les savoir-faire de leurs voisins puisqu'elles travaillent dans leurs champs, les femmes twa refusent de sarcler les parcelles défrichées par leur mari ${ }^{11}$, préférant gérer leur temps à leur guise.

La forêt de terre ferme est propice à la chasse. Selon la coutume, les deux castes ont des droits sur leur territoire de clan commun (Müller 1958). La chasse est pratiquée par les deux castes, bien qu'elle marque l'identité des baTwa qui y consacrent davantage de temps. La chasse collective au filet n'a plus cours depuis les années 70, délaissée d'abord par les baOto, puis par les Pygmées, faute de filets et de transmission des savoir-faire (Pagezy 1975). En 1972, le gros gibier, tel que les éléphants de forêt, a déjà disparu, bien que l'on en trouve encore quelques individus dans les zones les plus reculées entre les lacs Tumba et Léopold II. L'hippopotame était chassé dans les roselières du lac Tumba jusque dans les années 50. Le bonobo, animal mythique, apprécié pour son goût et admiré pour sa force et son intelligence, était encore présent au sud du lac Tumba au début des années 1970 (Nishida 1972).

21 Les rives du lac ne sont habitées que par des descendants de pêcheurs d'eau profonde. Leurs savoirs sont immenses, en particulier ceux qui concernent le milieu subaquatique, la navigation, les poissons et leur mode de vie, ainsi que les différentes techniques de pêche, individuelle et collective (Pagezy 2006a). 
22 pêcheurs de rivière sont exclusivement baOto. Dans les campements, la plupart des techniques sont individuelles, parfois collectives sous le contrôle d'un maître de pêche tenant son pouvoir de la surnature. En 1990, le premier pêcheur twa a été autorisé à s'installer pour pêcher dans un campement sur la Lolo.

23 coret ino poissons, elle est drainée par le fleuve sur pusieurs kilomètres tout créateurs des poissons, elle est drainée par le fleuve sur plusieurs kilomètres tout en recevant les précipitations locales. Les techniques de pêche différencient les baOto des baTwa, et les hommes des femmes. Les barrages de nasses marquent l'identité des pêcheurs oto ; l'écopage des marigots, celle des femmes twa.

Photographie 9 : Grand barrage de pêche, aux basses eaux : on distingue quelques nasses

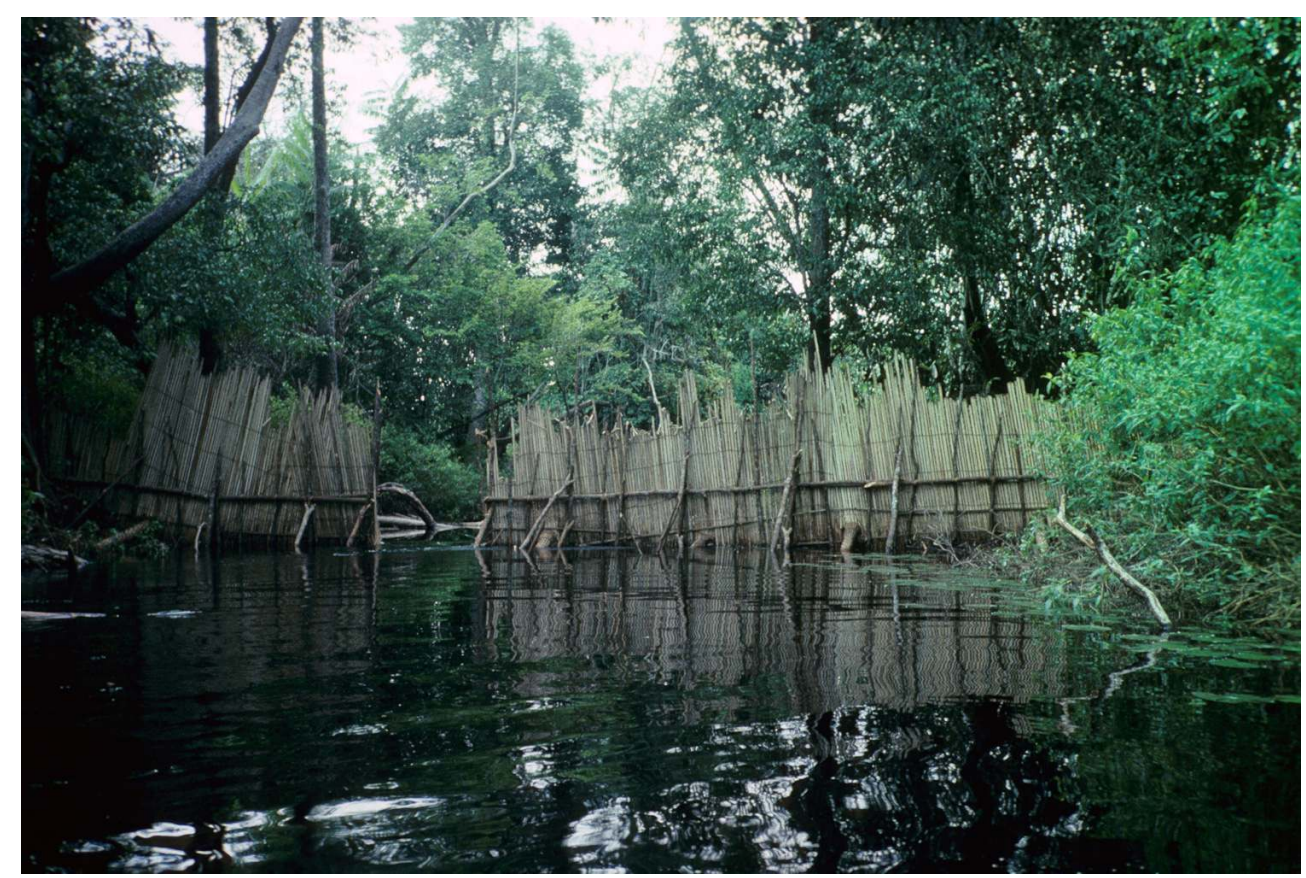

(c) H. Pagezy 
Photographie 10 : La pêche à l'écope aux basses eaux

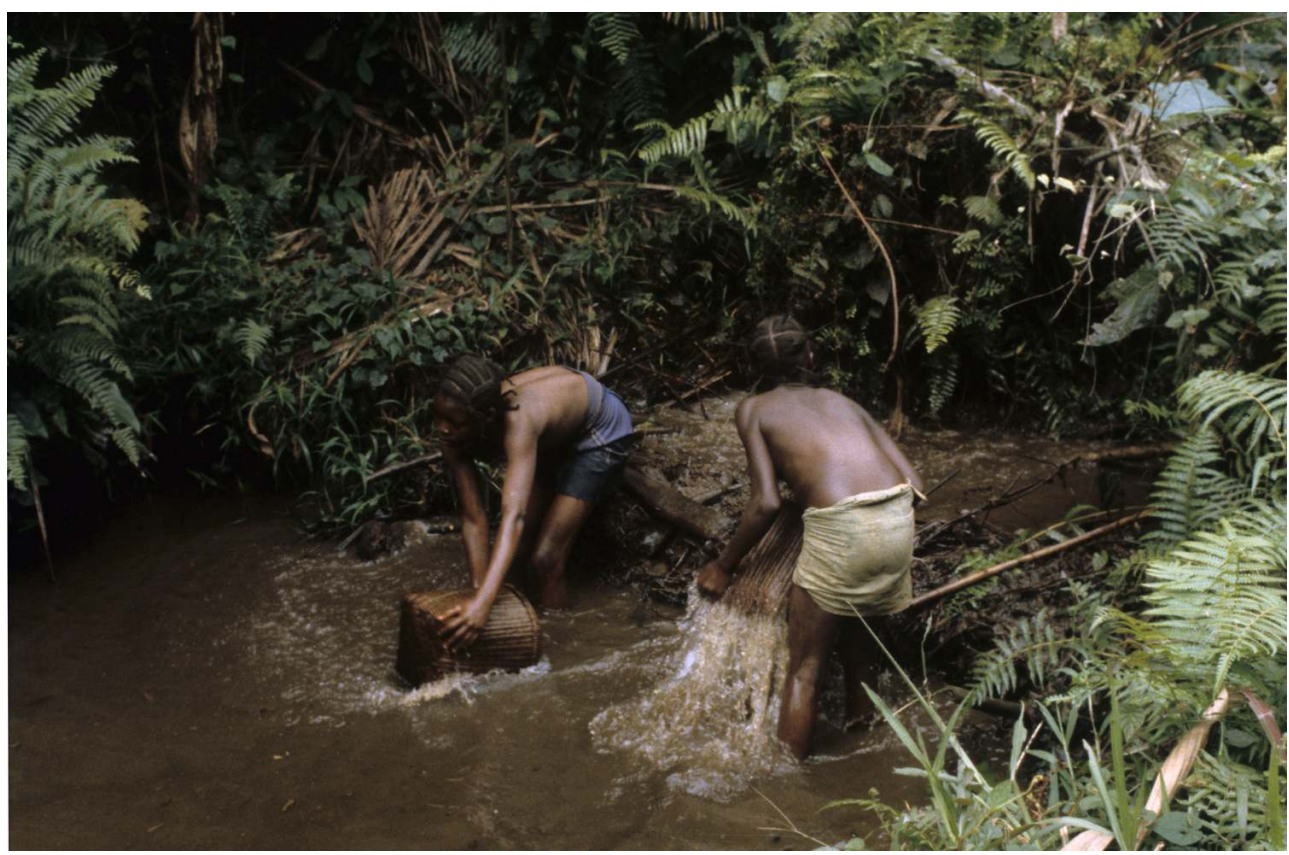

On vide des mares avec des paniers

(c) H. Pagezy

Les activités de production sur les ressources animales se succèdent à chaque saison (Figure 3), grâce à la complémentarité des deux castes dans l'occupation de l'espace et leurs techniques spécifiques d'appropriation (Pagezy 1995).

Figure 3 : Activités saisonnières des Ntomba en relation avec le régime des pluies (1971-1972)

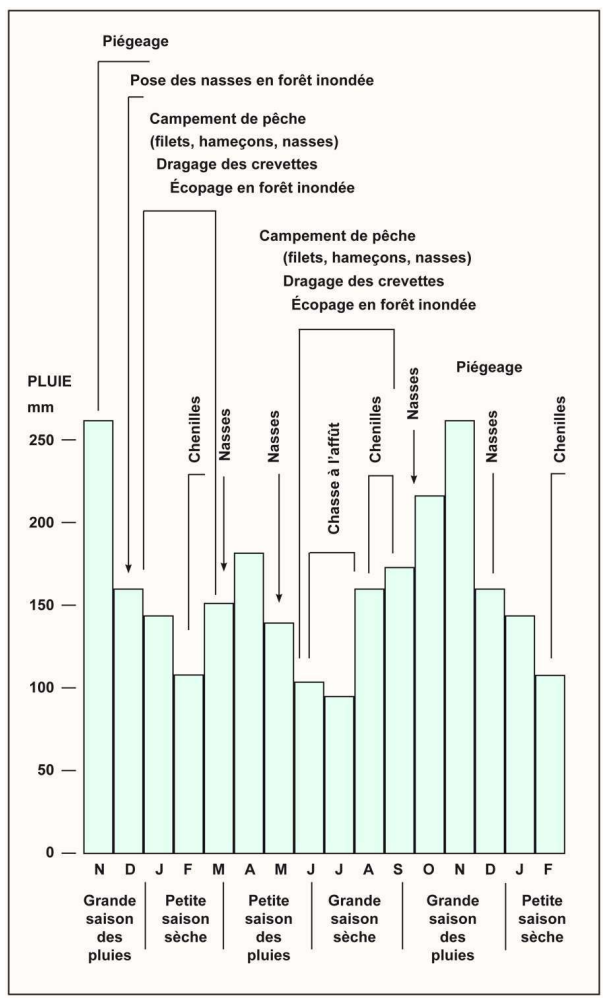




\section{Le petit commerce, les rétributions et les échanges différés} poisson contre l'hospitalité au cours d'un voyage. Les échanges de poisson contre du manioc caractérisent les relations entre castes et l'économie locale entre village et campements de pêche (Pagezy 2010). Ainsi, chaque famille oto ou twa possède son réseau social qui lui permet de défricher, cultiver, voyager, se marier.

\section{Régime alimentaire et état nutritionnel}

\section{Évaluation de l'état nutritionnel des Ntomba}

En fin de saison sèche (bonne saison) et en fin de saison pluvieuse (mauvaise saison), j'ai évalué de 1970 à 1972 la valeur nutritive du régime des Ntomba (Pagezy 1988a), sur la base d'une enquête familiale de consommation, en m'aidant de la table de composition alimentaire à l'usage de l'Afrique (FAO 1970). En 1979 et 1980 ont été effectués à chaque saison des examens cliniques et parasitologiques, tandis que nous avons conjointement relevé des indicateurs anthropométriques, sérologiques et hématologiques de l'état nutritionnel ${ }^{16}$. 


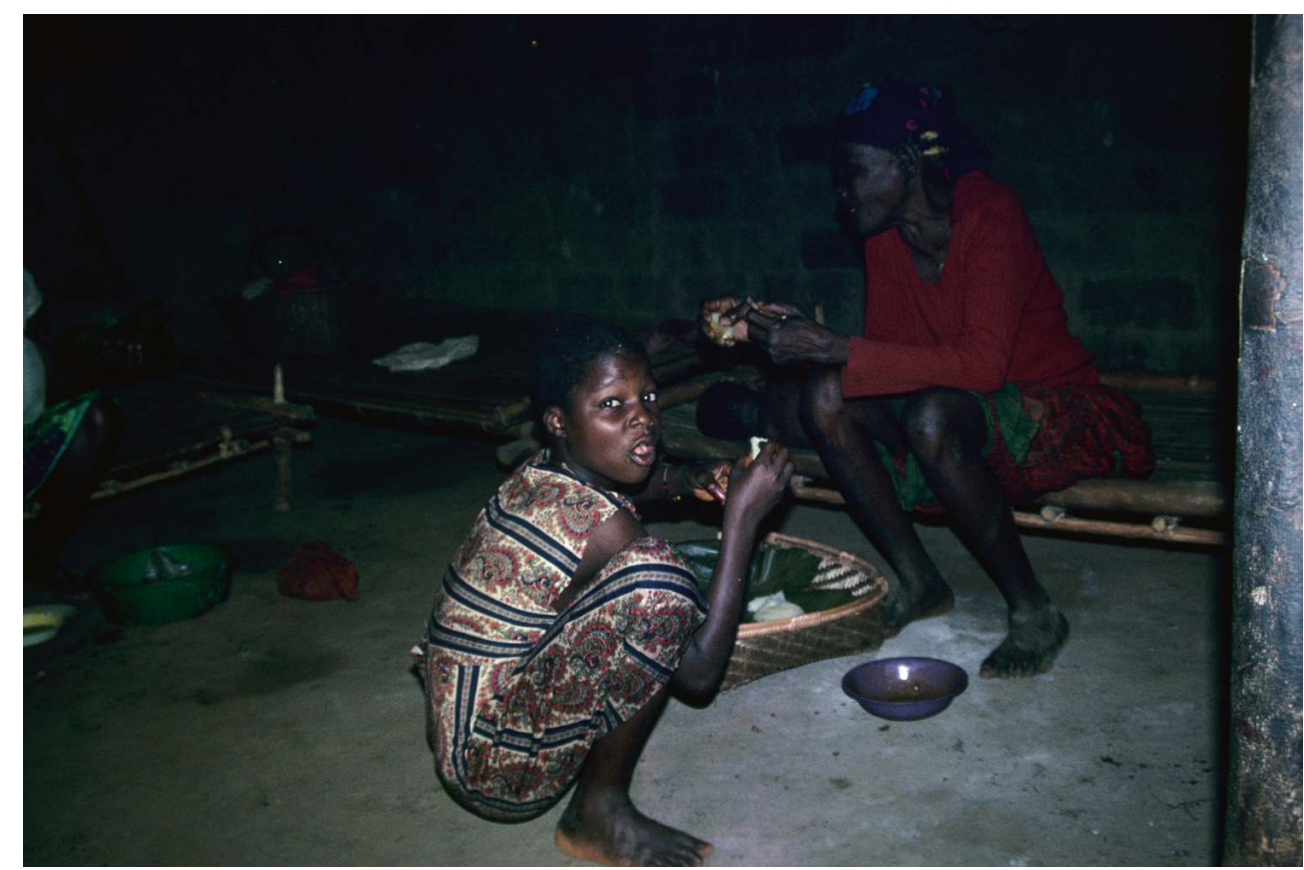

Les « bâtons » de manioc, déposés dans le panier plat, sont trempés dans la sauce, dans l'assiette (c) H. Pagezy

\section{Examens cliniques}

Les examens cliniques effectués en 1979 et 1980 ont inclus des palpations du foie, de la rate et de la thyroïde, ainsi que la mesure de la tension artérielle (voir tableau 5, en annexe).

31 L'hépatomégalie et la splénomégalie sont manifestes dès l'âge de 5 ans dans les deux sexes, en liaison avec la forte charge parasitaire (voir infra). Le goitre est quasiment absent du lac Tumba, à la différence des régions de l'Oubangui et du nord de la province de l'Équateur, grâce au long rouissage du manioc (une semaine), technique ayant pour effet de le débarrasser de sa teneur en acide cyanhydrique et de son goût amer (Ermans et al. 1980). Les cas d'hypertension sont rares et portent sur la pression diastolique. La consommation de sel est limitée par son approvisionnement ou son prix, surtout pour les baTwa.

\section{Parasitologie des selles et du sang}

32 La charge parasitaire intestinale en ascaris est très élevée dès la petite enfance. Liée à l'ingestion d'aliments souillés, elle serait imputable en priorité au manque d'hygiène dans un milieu favorable à la prolifération de microorganismes. En ce qui concerne les trichocéphales, les prévalences comme les charges parasitaires sont moins élevées chez les baOto. Les baTwa affichent une charge supérieure à celle des baOto, protégés par un meilleur accès aux vermifuges (voir tableaux $6 \mathrm{a}$ à $6 \mathrm{~d}$, en annexe).

33 L'ankylostomiase touche plus de $70 \%$ de la population dès l'âge de 2 ans. Responsable d'importantes déperditions de fer, elle participe à la détérioration de l'état nutritionnel. 

filaires (Dipetalonema) et les Plasmodium du paludisme. Au lac Tumba, la charge parasitaire en microfilaires est très élevée à partir de 20 ans, surtout chez les baOto, celle-ci pouvant atteindre 6403 microfilaires pour 35 microlitres de sang chez un homme (tableau 7a, en annexe). Bien que présente, la loase est rare. L'abondance des filaires concorde avec l'importance de polynucléaires éosinophiles dans le sang quels que soient le sexe et l'âge (tableau $7 \mathrm{~b}$, en annexe).

Les taux d'hémoglobine et l'hématocrite sanguins des baOto ont été mesurés sur place par microméthode en fin de saison des pluies $^{17}$. Le village de Nzalekenga souffre d'anémie chronique quels que soient la caste, le sexe et l'âge (tableaux $8 \mathrm{a}$ et $8 \mathrm{~b}, 8 \mathrm{c}$ et $8 \mathrm{~d}$ en annexe), les baTwa sont plus anémiés que les baOto, les femmes que les hommes et les jeunes que les adultes. Les déficiences enzymatiques héréditaires (G6PD), la carence en fer (ferreux), le parasitisme intestinal (ankylostomiase chronique) et sanguin (paludisme) sont susceptibles de jouer un rôle important dans l'installation et le maintien de l'état chronique d'anémie. Rappelons que cet état affecte l'aptitude physique à l'effort, tandis qu'une anémie modérée pourrait être compatible avec la capacité de résister aux infections (Walter et al. 1997). Le minimum absolu a été observé chez une femme twa dont le taux d'hémoglobine était de 5,1g/100 ml et qui, malgré cela, ne semblait pas pénalisée par ce faible score. Elle écopait à la même cadence que les autres femmes et était bien intégrée dans son groupe. Pourtant l'écopage est l'activité biologiquement la plus coûteuse bien que perçue comme moins pénible par les femmes twa (voir note 11).

\section{Indicateurs sérologiques (albumine, transferrine, IgG, IgM)}

37 Les protéines plasmatiques comportent deux fractions. L'albumine et la transferrine, sensibles à la teneur en protéines du régime alimentaire, sont des indicateurs de l'état de nutrition protéino-énergétique tandis que les immunoglobulines qui réagissent à l'environnement pathogène sont des indicateurs de l'état infectieux et inflammatoire (Pagezy 1988a). Si les protéines totales sont satisfaisantes dans les deux castes, (> 7g/100 $\mathrm{ml}$ ), leurs deux composantes sont fortement déséquilibrées.

Le taux d'albumine des adultes, bien inférieur à la valeur de référence (4641 mg/100 ml) de Siccardi et al. (1986), diminue avec l'âge et durant la saison des pluies, saison de « faim» (tableaux 9a et 9b, en annexe).

Les infections affectent l'immunité par l'accroissement des immunoglobulines (Scrimshaw, Taylor \& Gordon 1971). Les IgM représentent une réponse humorale immédiate, tandis que les IgG une réponse à plus long terme. Les deux types d'immunoglobulines (tableaux 10a et 10b en annexe) ont des valeurs particulièrement élevées dans les deux castes, quel que soit le sexe, reflet d'une réponse adaptative aux pressions du milieu pathogène. Elles augmentent chez les personnes âgées et chez les 
baTwa, probablement en liaison avec le mode de vie de ces derniers et leur plus mauvaise couverture sanitaire.

\section{Indicateurs anthropométriques}

40 Les mensurations anthropométriques ont été effectuées en fin de saison sèche (bonne saison) et en fin de saison pluvieuse (mauvaise saison) de 1979 et $1980^{18}$. Les variables anthropométriques choisies représentent des indicateurs de l'état de nutrition; leur variation renseigne sur les modifications morphologiques et physiologiques liées à la mobilisation des réserves énergétiques (épaisseur de graisse sous-cutanée) et la mobilisation des protéines musculaires (circonférence maigre du bras) lorsque les besoins en énergie ne sont pas couverts.

41 Chez les hommes, en saison sèche, les scores des baTwa sont inférieurs à ceux des baOto. Les différences portent particulièrement sur la circonférence maigre du bras et le pli cutané sous-scapulaire, variables sensibles à la réduction des activités physiques durant cette saison. Les variables anthropométriques sont inégalement affectées selon les classes d'âge; la dégradation de l'état nutritionnel touche particulièrement les personnes âgées (Pagezy 1982).

Quel que soit leur âge, les femmes sont affectées par la contrainte saisonnière pour toutes les mensurations, excepté la circonférence maigre du bras (Pagezy 1984). Quant aux enfants, leur croissance ralentit durant la mauvaise saison pour rebondir à la saison sèche suivante (Pagezy \& Hauspie 1985, Pagezy 1988a).

\section{Valeur adaptative du régime de sevrage}

Chez les baOto comme chez les baTwa, l'allaitement seul dure entre 2 et 6 mois (Pagezy 1988a, Pagezy 1993). Le sevrage débute avec les aliments liquides, jus de fruits sauvages ou cultivés (orange, papaye), bouillon issu du plat familial non pimenté, et sauce de noix de palme. Puis viennent les aliments les plus tendres, graisse et foie de gibier ou de poulet, poisson frais bouilli sans arêtes, que la femme pétrit dans sa main avant de le présenter au bébé. Entre 7 et 11 mois l'enfant reçoit des aliments plus compacts (manioc pilé, banane plantain), des beignets et des chenilles. Le sevrage se termine après 14 mois par la présentation de beignets (baOto), chenilles, maïs, arachides, ananas, canne à sucre. En 1970-72, le sevrage définitif (fin de l'allaitement) est tardif, compris entre 13 et 24 mois (P50=16 mois) chez les baOto, entre 16 et 36 mois (P50 = 22 mois) chez les baTwa (Pagezy 1988a). Vingt ans plus tard, la tendance est à un sevrage définitif de six mois plus précoce chez les baOto comme chez les baTwa. Le lait devient progressivement un complément alimentaire de l'allaitement, qui reste un moment important de la relation mère-enfant.

Il est intéressant de constater que les aliments présentés à l'enfant ne sont jamais spécialement préparés pour lui, un avantage pour la mère qui économise son temps et pour l'enfant qui est conditionné de façon précoce aux goûts les plus répandus de sa société. Il n'y a que le piment qui ne soit pas proposé au bébé. Jusqu'à son sevrage et même au-delà, la mère partage sa propre part avec le dernier né. Celui-ci dirige son sevrage en acceptant ou refusant le nouvel aliment (Pagezy 1988a, Pagezy 1993). En 1990, la bouillie de maiis, introduite par la mission protestante de Ntondo, responsable du programme de surveillance nutritionnelle dans la région, a été à l'origine d'un effet pervers, conséquence de la mauvaise image du manioc pour les nutritionnistes. Appelée 
"énergie ", la bouillie de maïs devait remplacer celle de manioc, sous prétexte d'une teneur en protéines supérieure. Pourtant, les céréales possèdent un médiocre taux de protéines rapporté au poids frais; de plus, elles sont carencées en lysine, acide aminé essentiel. Faute de moulin, le maïs demande beaucoup d'effort et de temps aux mères pour l'écraser, tandis que les enfants acceptent mal cette farine grossièrement moulue et non sucrée. Aussi, les villageois ont détourné cet aliment de sa fonction d'aliment de sevrage, pour fabriquer du lotoko, alcool de maïs et de manioc, destiné à faire face à la pénurie de bière suite à la fermeture de la brasserie de Mbandaka. Le plus cocasse était que les missionnaires complimentaient les parents pour l'extension de leurs plantations de maïs nouvellement introduit comme aliment de sevrage sous l'appellation d'« énergie »! (Pagezy 1995).

\section{Alimentation des jeunes enfants}

Après le sevrage, l'enfant rejoint le groupe des prépubères, avec qui il entre en compétition au niveau du plat commun. À partir de cinq ans il participe avec ses aînés aux activités de collecte-ramassage de fruits sauvages, champignons, chenilles - et de pêche au fretin dans les marais en contrebas du village. Les jeunes garçons capturent les micromammifères et les oiseaux, à l'arc et dans leurs pièges. Tacitement réservées aux enfants, les espèces de petite taille sont dénigrées par les hommes adultes, surtout les vieux, par crainte de moquerie. En partie consommés sur place, ces aliments sont en partie rapportés au domicile. Partagés entre enfants, ils sont cuits dans les braises ou sur un brasero à l'occasion d'une petite dinette. Lorsqu'il est intégré au repas familial ce bonus nutritionnel favorise l'enfant-producteur (Pagezy 1993).

Photographie 12 : Repas d'enfants

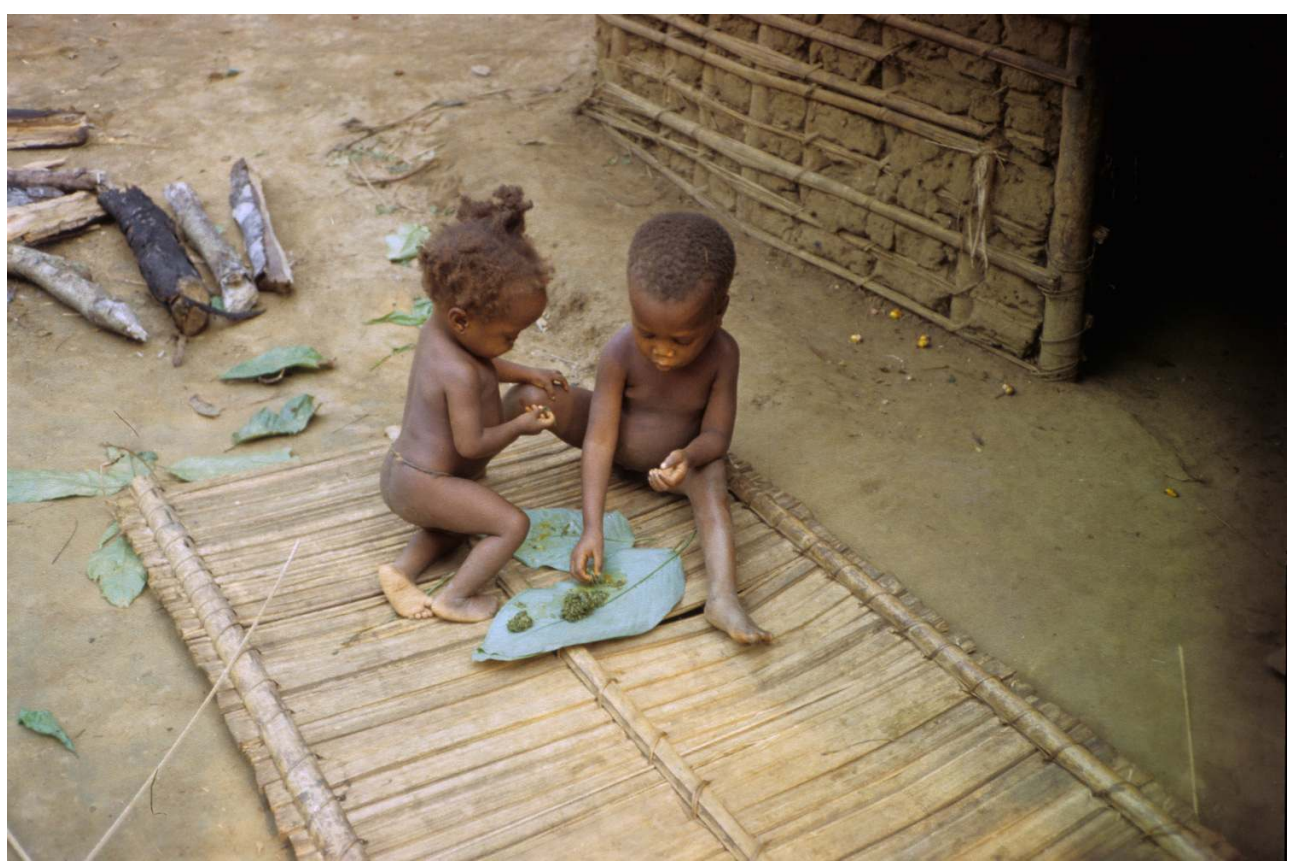

(c) H. Pagezy 


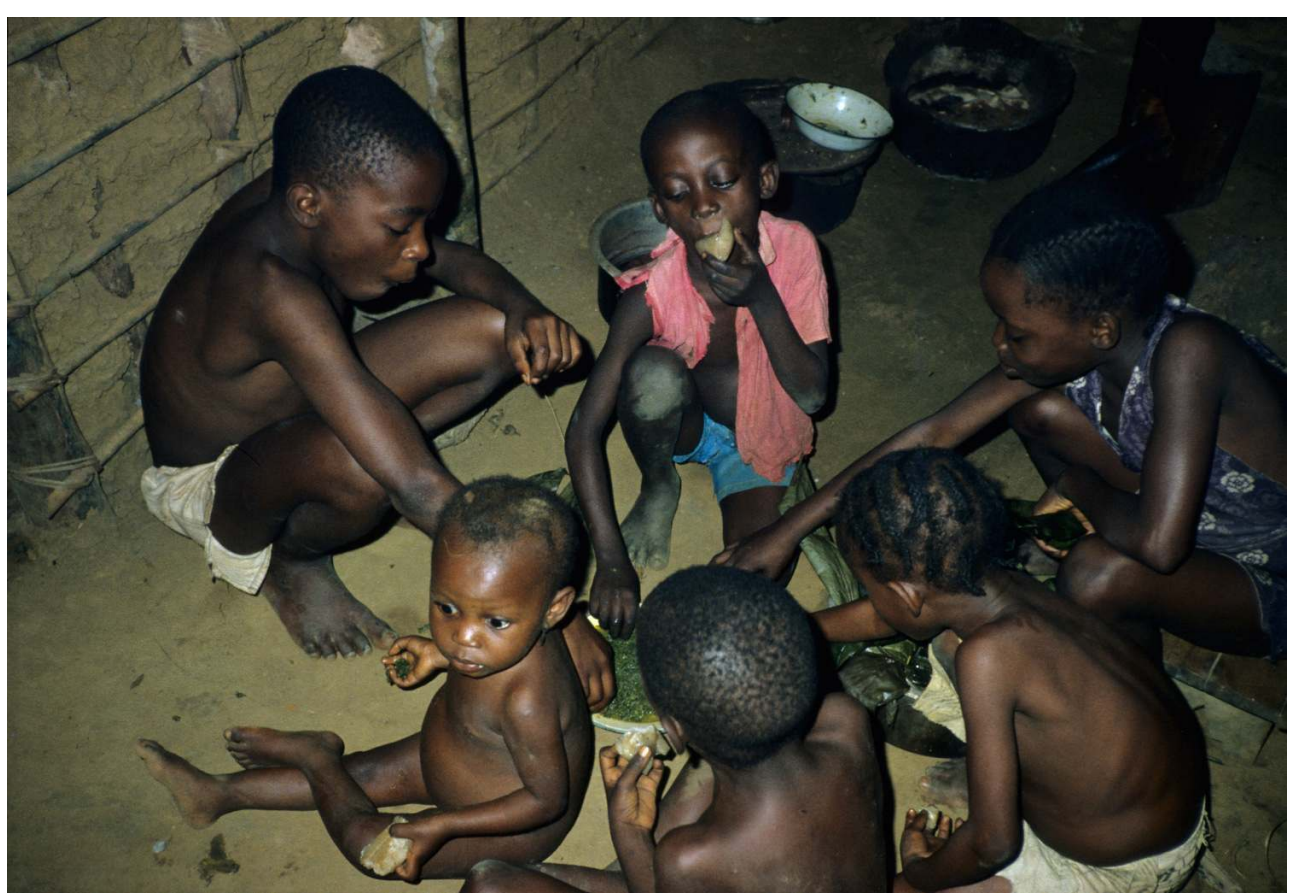

Le bâton de manioc est tenu dans la main gauche, pendant que l'on prend des feuilles de manioc dans le plat

(C) H. Pagezy

\section{Poids des interdits alimentaires dans le partage intrafamilial} personne au sein de sa société (Garine 1980, Pagezy 2006b). La plupart d'entre eux sont temporaires; ils sont levés sous prétexte d'ignorance ou de "vol » dans la marmite par l'enfant. Plus rares sont les interdits permanents ; il s'agit en général d'interdits de clan, ou encore d'espèces à haute charge symbolique, susceptibles d'entraîner la mort.

Les femmes et les enfants des deux sexes sont particulièrement visés par les interdits alimentaires. Jusqu'à 15 ans, âge auquel il acquiert son statut d'adulte en pratiquant seul et avec succès les activités de subsistance liées à son genre (chasse et pêche), le garçon est assimilé au genre féminin, tandis que c'est par son premier accouchement et surtout par l'allaitement, que la jeune fille acquiert son statut de femme, mère des enfants (Pagezy 1983). Les hommes sont grandement épargnés par les interdits de genre, excepté les marqueurs du genre féminin : le poisson électrique ntula, la grosse larve de coléoptère $i k y o$ et une espèce de termite chez les baTwa. En revanche, certaines espèces de gibier, rares et prestigieuses, à haute charge symbolique, telles que le léopard, l'aigle couronné et le daman des arbres, sont réservées aux plus âgés et plus particulièrement aux chefs (Pagezy 1975).

48 Certaines personnes sont aimées des esprits qui leur accordent la fécondité-parents de jumeaux, femme primipare; d'autres sont possédées par des esprits maléfiques qui perturbent l'harmonie familiale, la normalité culturelle ou la fertilité des femmes. Les femmes mpo sont sujettes à stérilité secondaire, les enfants ingondo ont leur première dent poussant à la mâchoire supérieure (anormalité), d'autres personnes sont possédées 
(anormalité) par les esprits elima, soonde, mpombo ou ntambu. Leur traitement consiste en une psychothérapie de groupe chez un guérisseur lui-même ancien(ne) possédé, un régime à base de plantes spécifiques, et en séances de danse accompagnées d'instruments consacrés, que le possédé exécute entouré d'anciens possédés (Pagezy 1975). Chaque membre de la confrérie doit respecter des interdits alimentaires spécifiques.

Au temps de la colonisation, les interdits alimentaires étaient accusés par les médecins de dégrader l'état nutritionnel des femmes et des enfants, catégories biologiquement vulnérables. Chez les Ntomba, les espèces interdites, bien que nombreuses, ne sont pas les plus fréquentes dans le régime quotidien. Ainsi, certaines, comme le céphalophe bleu ( Cephalophus monticola) et la plupart des poissons, très présents dans le régime, ne sont pas concernés (Pagezy 2006b). Par ailleurs, l'impact nutritionnel des interdits alimentaires est limité par la raréfaction (ou la disparition) de certaines espèces et l'abandon des interdits les moins chargés symboliquement, conséquence de la pression sur les ressources naturelles et des changements de mentalité.

\section{Le régime des femmes primipares}

Comme de nombreuses régions d'Afrique centrale (Romaniuk 1967), la Cuvette centrale a été le siège d'une importante infécondité, imputable aux stérilités primaire et secondaire, et par une longue période d'allaitement, susceptible de freiner la fécondité en bloquant l'ovulation (Retel-Laurentin 1974, Sala-Diakanda 1980). Ce contexte d'infécondité a régressé entre 1970 et 1990, suite à de nombreux facteurs, en particulier la large utilisation des antibiotiques.

51 Chez les Ntomba, la femme primipare, appelée Molekele ou Wale, bénéficie d'un prestige inégalé. Comme les parents de jumeaux, elle appartient à une catégorie aimée des esprits, en particulier de Mama Mpia, génie qui accorde la fertilité aux femmes qui l'invoquent. Durant ses deux à quatre années de réclusion, elle est considérée comme l'égale d'Ilanga i I'Iolia, le grand chef coutumier des Mongo du sud. Elle doit suivre des interdits sur les activités qui marqueront sa vie future de productrice et reproductrice: cultiver les champs et avoir des relations sexuelles même avec le père de son enfant. En contaminant le lait maternel, le sperme est censé empoisonner le bébé (Pagezy, 1983). La Wale est avantagée dans le partage de la nourriture - viande, poisson, manioc, feuillage, sauce ou huile de palme - même par rapport au chef de famille. Surveillée le jour par ses chaperons et la nuit par sa mère qui partage sa case de réclusion, elle dort dans un lit clos, Elle partage son repas avec son enfant, qui est aussi l'objet d'attention de tous. 


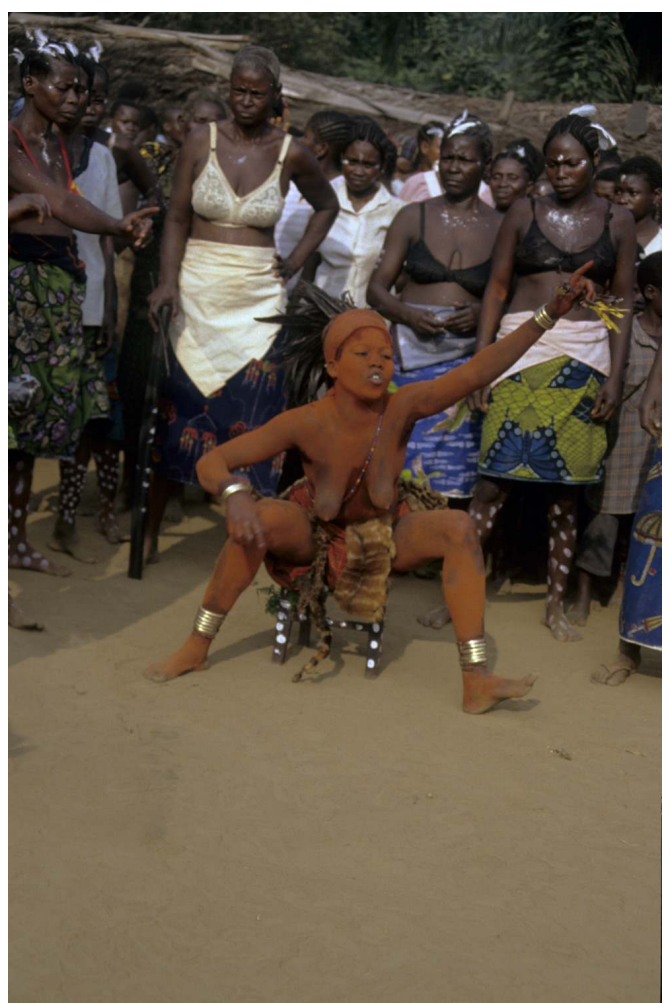

Lorsqu'elle accouche de son premier enfant, la jeune femme est recluse dans sa maison pendant plusieurs années, consommant une nourriture riche. Cette période se conclut par une cérémonie de sortie, où la Wale apparaît ornée et enduite de pâte de bois de Padouk (Pterocarpus soyauxii)

(c) H. Pagezy

Par son régime alimentaire, riche en qualité et en quantité, l'interdiction d'activités physiques qui marqueront sa vie de femme et l'attention constante de son entourage, la femme primipare ntomba (oto comme twa), à un moment critique de sa vie, réalise un statut nutritionnel qu'elle ne retrouvera jamais plus, lui permettant de faire face à ses activités futures de production et reproduction. Simultanément, son enfant premier né, de faible poids de naissance, rattrape la courbe pondérale locale (Pagezy 1996).

\section{Effet saisonnier de la fréquentation des campements de pêche}

Le régime alimentaire des Ntomba présente d'importantes différences entre village et campements de pêche. Dans les campements, quelle que soit la saison, l'alimentation des pêcheurs et de leurs invités ${ }^{19}$, est riche en protéines animales, provenant essentiellement de l'abondance du poisson frais de rivière (Pagezy 1986, Pagezy 1992). La «faim de viande " y est inconnue. Il s'ensuit un état nutritionnel meilleur que dans les villages (excepté celui des enseignants), au vu d'indicateurs anthropométriques (tableau 11 en annexe) et sanguins (tableau 12 en annexe). Néanmoins, les taux d'immunoglobulines sont toujours très élevés (Pagezy 1988a). Sous l'angle de l'état nutritionnel, la mobilité saisonnière vers les campements apparaît comme une réponse culturelle biologiquement adaptée ; les villageois s'y refont une santé en rattrapant leur statut nutritionnel élevé. Toutefois, il arrive que ce mécanisme de récupération soit dépassé. Par exemple lorsqu'une mauvaise année fait suite à une mauvaise saison. 
Photographie 15 : Camp de pêche

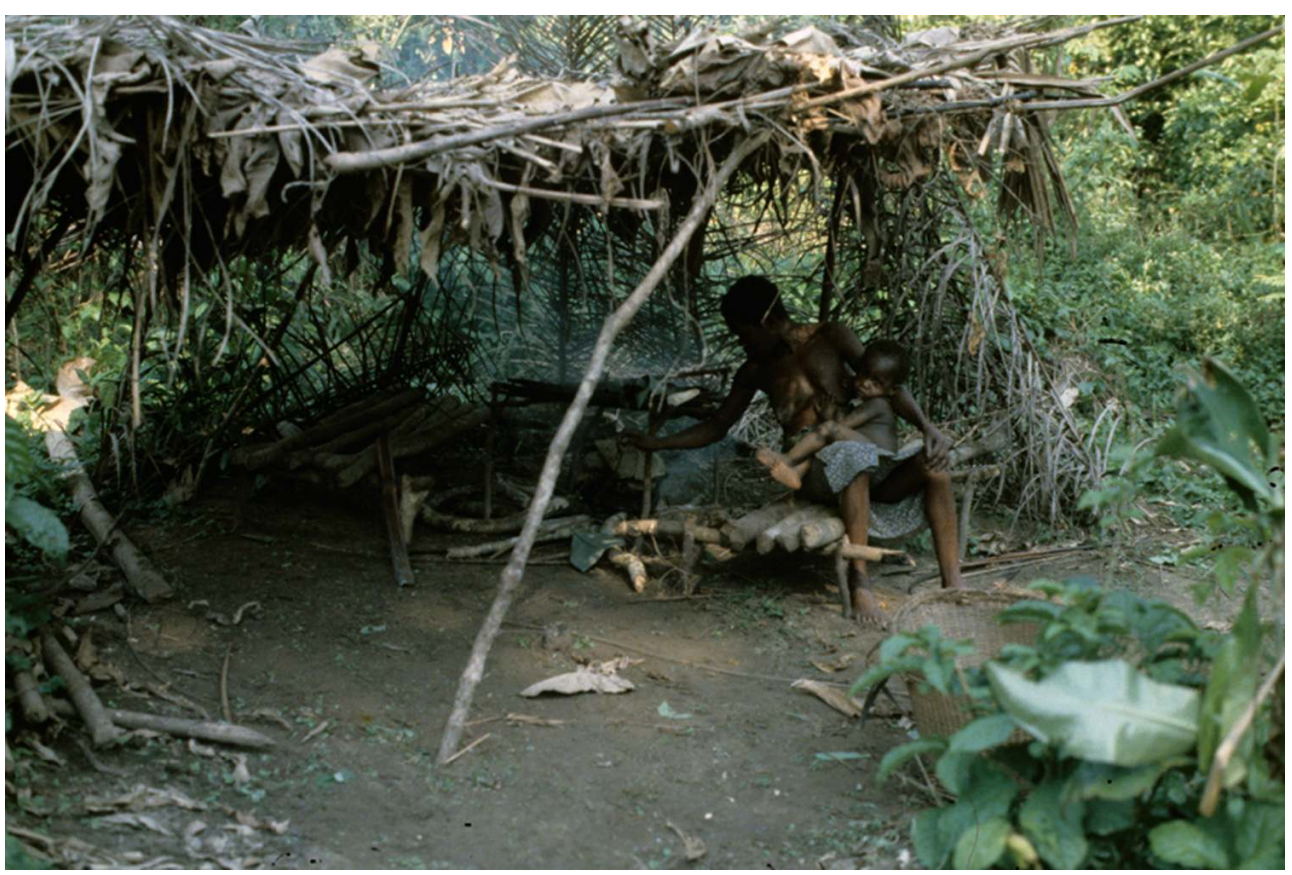

(c) H. Pagezy

Photographie 16 : Bascule de pêche

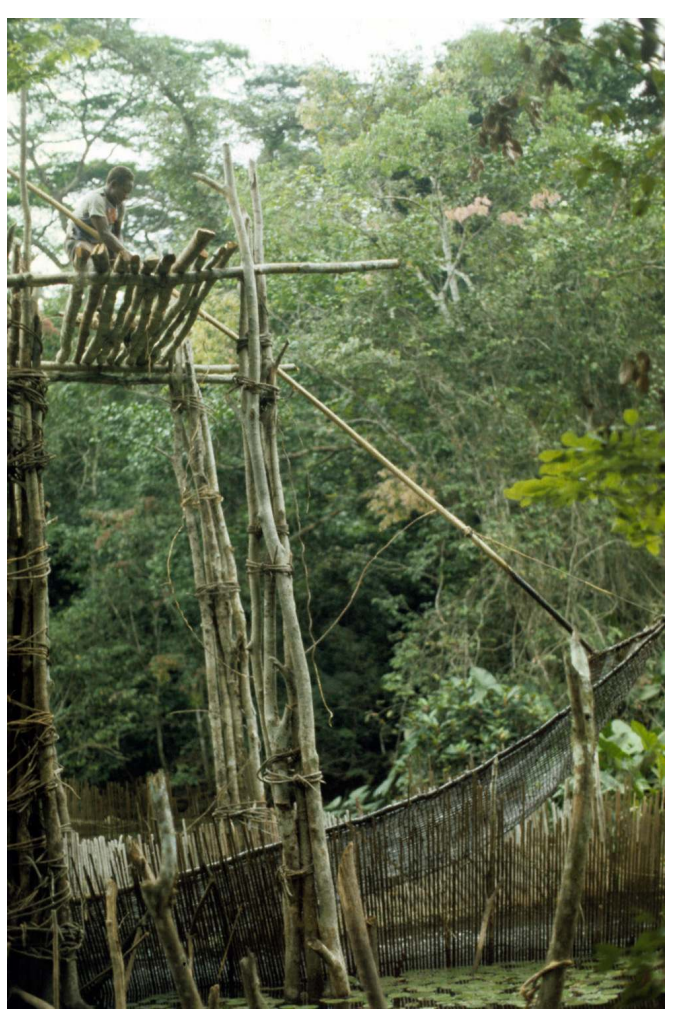

Les engins de pêche sont très diversifiés, adaptés à tous les milieux, marais, lac, rivières, et s'employant aux diverses saisons

(c) H. Pagezy 


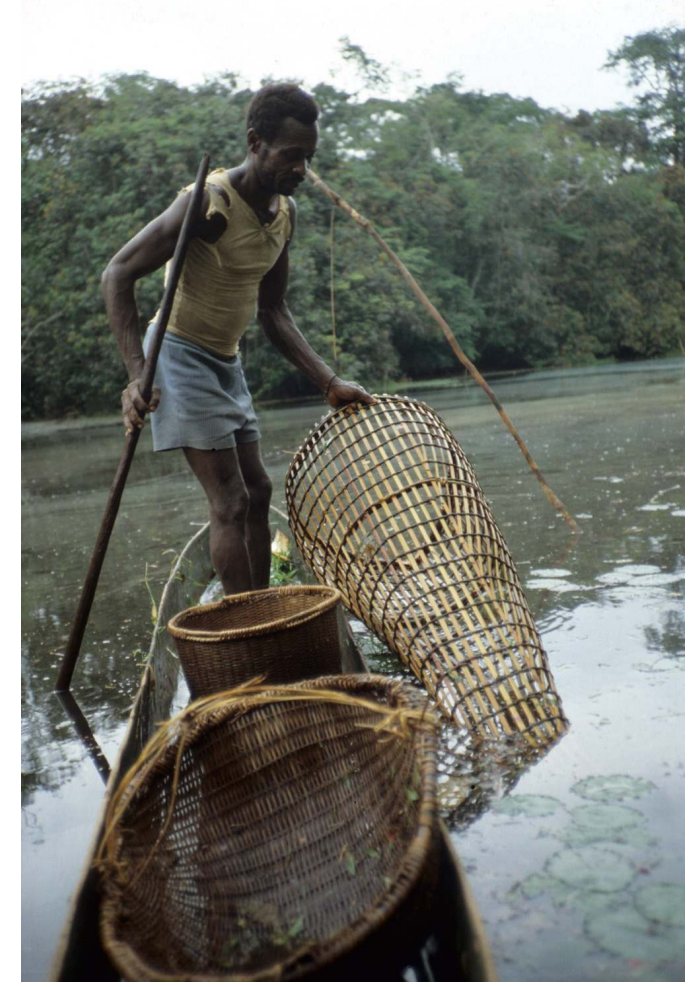

(c) H. Pagezy

Pour pallier le risque de dégradation des conditions de vie, les habitants de Nzalekenga ont répondu par la migration. Entre 1970 et 1980, j'ai pu observer un mouvement irréversible de sédentarisation de pêcheurs saisonniers dans les principaux campements de pêche situés sur la rivière Lolo, tandis que même certains baTwa devenaient pêcheurs (Pagezy 2000). Poussés par la situation économique désastreuse, l'accroissement démographique du village, lié à la disparition de la stérilité (cf. ci-dessus), les pêcheurs ont progressivement allongé leur durée de séjour dans les campements, empiétant de plus en plus sur la saison des pluies. Ils ont peu à peu défriché la forêt pour y planter du manioc, et ont construit des habitations durables en remplacement des huttes temporaires, pour finalement s'y installer avec leur famille. En revanche, les baTwa ne les ont pas imités, se limitant toujours à des va-et-vient entre village et campements. Entre 1980 et 1990, l'émigration a aussi concerné des villageois non pêcheurs, fuyant la promiscuité et l'usure d'une terre incapable d'accueillir de nouvelles plantations. Ainsi, quelques familles oto ont fondé de nouveaux quartiers, dans la forêt, à distance du village, sur des terres, isolées mais plus riches, appartenant à leur clan (Pagezy 2000).

\section{Synthèse sur 20 années}

Les relations entre biodiversité et alimentation dans la société ntomba se sont maintenues pendant de longues années, grâce à la diversité des biotopes et la complémentarité des activités de subsistance entre villageois et Pygmées. Cette situation, idéale sous l'angle de l'alimentation et de l'état nutritionnel, leur a permis de s'ajuster aux changements de l'environnement, des conditions de vie et des valeurs traditionnelles. 
Parmi les facteurs susceptibles de conduire au déséquilibre entre biodiversité et alimentation, citons les changements économiques, démographiques, et socio-culturels.

\section{Changements socio-économiques}

56 Jusqu'en 1970, le mode de vie était plus proche de celui prévalant durant la période coloniale, avec ses aspects négatifs, tels que les comportements discriminatoires, les travaux imposés, l'entretien des routes, les vexations. Les aspects positifs ${ }^{20}$, découlant du comportement paternaliste du colonisateur, n'étaient pas pour autant négligeables. Dans les plantations, les salaires décents étaient accompagnés d'avantages sociaux dans un contexte de forte croissance économique et de monnaie forte : avance sur salaires, soins médicaux, accès aux coopératives gérées par l'entreprise. Les baTwa quant à eux, bénéficiaient au village d'une irresponsabilité pénale et d'un droit d'usage sur le territoire de clan $^{21}$. Leur engagement dans les plantations était transitoire et opportuniste. Des changements majeurs survenus au cours des vingt années suivantes ont accompagné la catastrophique zaïrisation du pays, imposée par Mobutu: récession économique, changement et dévaluation de la monnaie, régression des avantages en nature et des salaires dans les sociétés forestières, décidés par les nouveaux patrons incompétents. Les salaires des saigneurs twa atteignaient en 1991 à la CEQUA de Bikoro (plantation d'hévéa), l'équivalent de deux cigarettes par jour (Tardieu 1992).

En 1970, les Ntomba vivaient pratiquement en autarcie dans des biotopes riches en biodiversité, utilisés de façon complémentaire par l'une ou l'autre caste. L'argent, très rare, constituait une étape intermédiaire du système de troc. La monnaie traditionnelle et les anneaux de cuivre réservés à la dot avaient depuis peu disparu; les ma.kuta, subdivision du zaïre, ne valaient déjà plus rien.

Jusqu'à cette époque, les commerçants portugais, installés en ville avec leur famille, organisaient des tournées bimensuelles entre Mbandaka et leur plantation de café, tout en surveillant les boutiques de brousse, tenues par des gérants locaux. Indispensables à la vie économique de "l'Intérieur », ces boutiques étaient approvisionnées en articles les plus courants et les plus demandés. Expulsés à partir de 1973 - devançant les Belges - ils ont été remplacés par des Pakistanais inexpérimentés et inadaptés, non intéressés par le développement de l'Intérieur. Vers la fin des années 1980, le transport routier local a fait place à des baleinières, bateaux à fond plat, construits dans les chantiers du Bandundu, proches de Kinshasa. Leur objectif était d'utiliser la voie fluviale pour les échanges commerciaux, dont la finalité première était d'approvisionner la capitale. Certaines baleinières ont remonté le fleuve jusqu'au lac Tumba et les principaux campements de pêche. Le réseau routier et par voie de conséquence Mbandaka, la capitale de province, furent abandonnés, tandis que le commerce se faisait directement avec la capitale.

\section{Changements socio-démographiques}

Les changements démographiques ont eu des effets perceptibles à partir années 70, en raison de facteurs tels que :

- l'amélioration de l'état de santé par la diffusion de médicaments comme les antibiotiques, dont l'usage ne fut pas limité aux maladies infectieuses. Il s'en est suivi, semble-t-il, un effet collatéral sur l'infécondité imputable aux maladies vénériennes introduites par le colonisateur, tandis que l'on observait parallèlement le relâchement de 
l'interdit de relations sexuelles et de la longue durée d'allaitement. En 1990, les femmes non ménopausées ne consultaient plus pour stérilité comme en 1970, mais pour... hyperfécondité, ayant mis au monde plus de cinq enfants avant 35 ans, soit bien avant la ménopause ! Quant à l'usage des préservatifs, introduits à la fin des années 80 pour lutter contre le Sida, il était peu répandu - par quelques médecins dont une missionnaire - et à usage multiple ;

- la poussée démographique qui, au début des années 90 à Nzalekenga, a incité certaines familles à migrer vers des territoires de clan abandonnés ou à se sédentariser dans les campements de pêche (Pagezy, 2000);

- la dégradation de la qualité de vie, en particulier dans les grandes plantations. Traditionnellement, la mobilité vers les grandes plantations, était une stratégie temporaire permettant de résoudre un besoin financier momentané, en profitant d'un salaire fixe et de substantiels avantages sociaux. Pour les baTwa, il s'agissait aussi d'acquérir un nouveau statut social en échappant au mépris des baOto. Cependant, conséquence de la zaïrisation, tous les étrangers, commerçants et cadres de grandes plantations, implantés dans ces régions isolées ont été remplacés par des dirigeants nommés par le président, cupides et inexpérimentés, vivant en ville ou à la capitale, peu motivés et peu présents. Les avantages dispensés par des sociétés comme la CEQUA, exploitant le caoutchouc près de Bikoro, se sont taris, tandis que la superficie exploitée a été réduite de $90 \%$ en moins d'une dizaine d'années (Tardieu, 1992). Il s'en est suivi une vague de retour des travailleurs vers les villages d'origine les plus proches. Seuls quelques saigneurs twa ekonda et leur famille, se sont retrouvés piégés. Leur charge de travail s'est accrue pour un salaire de misère, sans aucune compensation sociale. Ces plantations étaient devenues, selon les missionnaires de Bikoro, des mouroirs.

\section{Changements socio-culturels et économiques}

Les changements socio-culturels ont marqué plus spécifiquement les baTwa. Ainsi, on remarque à partir des années 70 :

- Une avancée vers l'égalité des castes, débutée par la rupture avec l'ancien suzerain oto, suivie par la création de nouveaux quartiers ayant pour vocation de devenir de vrais villages dirigés par un chef pygmée. Finis les pénibles moqueries et mesquineries, le devoir de partage du gibier, mais aussi finis le paternalisme et l'irresponsabilité pénale. L'émancipation des baTwa a été aussi marquée dans leurs activités de subsistance. Qui aurait pensé 20 ans auparavant voir des hommes twa défricher leur propre plantation de manioc et leurs femmes les exploiter, ou s'installer en tant que pêcheurs dans un campement de pêche?

- En rapport avec l'environnement, les changements majeurs ont porté sur la gestion des ressources naturelles en particulier l'usufruit de la terre (ou de l'eau) accordé à certains pêcheurs oto et leurs descendants par les puissances surnaturelles. L'État n'ayant pas les moyens de faire respecter ses propres lois (enfreintes d'abord par ses fonctionnaires), il s'en est suivi une surexploitation incontrôlée des ressources - gibier et poisson en premier lieu - par des étrangers, militaires, citadins, ou jeunes de retour au village, chassés de la capitale par la récession économique.

- Dans le domaine de l'alimentation, les changements ont porté sur l'abandon de nombreux interdits. La plupart, temporaires, concernant les femmes et les enfants, étaient levés par leur changement de statut (jeunes filles devenant femmes, jeunes garçons capables de chasser et pêcher avec succès). Les espèces les plus communes dans le régime étaient 
rarement interdites. Le respect des interdits s'est relâché avec les nouvelles aspirations liées à la modernité (Garine 1980). Ainsi, seules les espèces les plus chargées symboliquement et aussi les plus rares sont restées interdites.

61 Les conduites liées au statut de la femme primipare et son enfant, avaient un effet positif sur l'état nutritionnel du couple mère-enfant, catégories vulnérables, car soumises aux contraintes biologiques liées à la croissance et à l'allaitement. La récession économique a généré un relâchement du respect des prescriptions relatives à la primiparité, en particulier l'abstinence sexuelle durant l'allaitement. Désirée, la femme Wale n'est pas restée intouchable. Le chaperon durant la journée, la mère ou de vieilles tantes la nuit, ont relâché leur surveillance afin de se libérer d'une personne dans un contexte de sévère récession économique. Quelle étrangeté de voir en 1991 certaines femmes Wale, n'ayant $\mathrm{pu}$ «sortir» faute de «moyens» (dot, trousseau), entourées de deux "premiersenfants", situation ayant comme effet d'aggraver leur situation en repoussant d'éventuels prétendants.

\section{Conclusion}

La présente étude a permis de mettre en évidence un ajustement entre l'importante biodiversité caractérisant la Cuvette centrale, et la possibilité de générer une alimentation saine et diversifiée au début des années 70. Malgré l'enclavement, le régime alimentaire des Ntomba permettait de répondre à la fois aux normes biologiques et socioculturelles de la société. En d'autres termes, la plupart des règles culturelles étaient biologiquement adaptées. La diversité des milieux, les savoirs et les savoir-faire, ainsi que la complémentarité des stratégies alimentaires des deux castes, leur permettaient d'avoir un état nutritionnel satisfaisant, compte-tenu des contraintes dominantes du milieu, en particulier de l'environnement pathogène. Selon les missionnaires attachées aux hôpitaux de brousse, les rares cas de malnutrition d'enfants étaient imputables à des comportements déviants de certains pêcheurs dont les effets se répercutaient sur l'état de santé de leurs enfants. Ils vendaient leur poisson aux commerçants itinérants, ou payaient en poisson les faveurs de commerçantes en visite plutôt que de l'envoyer - ou l'argent de la vente - à la famille restée au village. Ces cas isolés de malnutrition se sont amplifiés après la "zaïrisation Mobutu», en commençant par les catégories les plus vulnérables. Il semble que le point de non retour ait été atteint vingt années plus tard, les contextes économique et politique s'étant exagérément dégradés.

\section{BIBLIOGRAPHIE}

Aubréville A. 1949 - Climats, forêts et désertification. Paris, Société des éditions géographiques, maritimes et coloniales. 
Bouillenne R., Moureau J. \& Deuse P. 1955 - Esquisse écologique des facies forestiers et marécageux des bords du lac Tumba (Domaine de l'IRSAC, Mabali, Congo belge). Mém. Acad. Royale Sciences colon., Classe Sc. Nat., III (1), 42 p.

Dorst J. \& Dandelot P. 1972 - Guide des grands Mammiferes d'Afrique. Neuchâtel, Delachaux et Niestlé.

Elshout P. 1963 - Les Batwa des Ekonda. Musée Royal de l'Afrique Centrale. Tervuren, Belgique, Archives d'Ethnographie, $65 \mathrm{p}$.

Ermans A.M., Mbulamoko N.M., Delange F. \& Ahluwalia R. 1980 - Role of cassava in the etiology of endemic goiter and cretinism, I.D.R.C., 136e, Ottawa, $182 \mathrm{p}$.

F.A.O. 1970 - Table de composition des aliments à l'usage de l'Afrique, 218 p.

Garine I. de 1980 - Évolution contemporaine des croyances et interdits alimentaires. Présence africaine 113 : 129-146.

Garine I. de \& Pagezy H. 1989 - Faim saisonnière et faim de viande. In Se nourrir en forêt équatoriale : anthropologie alimentaire des populations des régions forestières humides d'Afrique : 43-44.

Hercberg S. \& Galan P. 1985 - Épidémiologie des anémies nutritionnelles et politiques de prévention. In Hercberg S., Dupin H., Papoz L. \& Galan P. (Ed.) Nutrition et santé publique : approche épidémiologique et politiques de prévention. Lavoisier : Techniques et documentation : 179-209.

Heywood P.F. \& Nurse G.T. 1980 - Regular seasonal hunger: a widespread phenomenon? In Singh I.P. \& Tiwari S.C. (Ed.) Man and its environment, Xth ICAES Series, $\mathrm{n}^{\circ}$ 2, P. Labita et S.C. Vidyarti, Concept publishing Company, New Delhi : 62-70.

Hulstaert G. 1961 - Les Mongo; aperçu général. Musée Royal de l'Afrique Centrale, Tervuren, Belgique. Archives d'ethnographie, vol. 5, 66 p.

Hulstaert G. 1966 - Notes de Botanique Mongo. Académie Royale des Sciences d'Outre Mer, Bruxelles, Classe des Naturelles et Médicales, N.S., T. XV, vol. 3, 212 p.

Jewsiewicki B. 1979 - Introduction to contributions to a history of agriculture and fishing in Central Africa. African economic history, $\mathrm{n}^{\circ} 7$, University of Wisconsin : 2-8.

Mamet M. 1955 - La langue Ntomba telle qu'elle est parlée au lac Tumba et dans la région avoisinante (Afrique Centrale). Annales du Musée Royal du Congo Belge, Tervuren, Belgique, Série in $8^{\circ}$, Sciences de l'homme, Linguistique, vol.11, 377 p.

Marlier G. 1958 - Recherches hydrobiologiques au lac Tumba. Den Haag : Uitgeverij Dr. W. Junk : 352-385.

Matthes H. 1964 - Les poissons du lac Tumba et de la région d'Ikela. Étude systématique et écologique. Musée Royal de l'Afrique Centrale, Belgique, Annales série in $8^{\circ}$, Sciences Zoologiques, $n^{\circ} 126$.

Miracle M.P. 1961 - Seasonal hunger: a vague concept and an unexplored problem. Bull. de l' IFAN, T. XXIII, série $B, n^{\circ}$ 1-2 : 273-283.

Müller E. 1958 - Le droit de propriété chez les Mongo-Bokote. Acad. Royale des Sc. Coloniales, Classe des Sciences Morales et Politiques, Mém. in-8 ${ }^{\circ}$, N.S. Ethnographie, IX (3), 79 p.

Müller E.W. 1964 - Die Batwa. Eine kleine wüchsige Jägerkaste bei den Mongo Ekonda. Z. Ethnol., vol. 89 : 206-215.

Nishida T. 1972 - Preliminary information of the Pygmy Chimpanzees (Pan paniscus) of the Congo Basin. Primates, 13 (4) : 415-425. 
Nurse G.T. 1975 - Seasonal hunger among the Ngoni and the Ntumba of Central Malawi. Africa 45 (1) : 1-11.

Ogbu J.U. 1973 - Seasonal hunger in tropical Africa as a cultural phenomenon. The Onich Ibo of Nigeria and Chakakapoka of Malawi examples. Africa, XIII (4) : 317-332.

O.M.S 1975 - Lutte contre les anémies nutritionnelles, en particulier contre la carence en fer. O.M.S., Série de rapports techniques $n^{\circ} 580$, Genève, $77 \mathrm{p}$.

Pagezy H. 1975 - Les interrelations homme-faune de la forêt du Zaïre. In L'Homme et l'Animal, 1er colloque d'Ethnozoologie, juin 1975. Paris, Inst. Int. Ethnosciences : 63-88.

Pagezy H. 1976 - Quelques aspects du travail quotidien des femmes Oto et Twa vivant en milieu forestier équatorial (lac Tumba, Zaïre). L'Anthropologie, Paris, Masson, 80 (3) : 465-490.

Pagezy H. 1982 - Seasonal hunger as experienced by the oto and the twa of a Ntomba village in the equatorial forest (lake Tumba, Zaïre). Ecol. Food and Nutr. vol. 12 : 139-153.

Pagezy H. 1983 - The attitude of the Ntomba society towards the primiparous woman and its biological effects. J. biosoc. Sci. 15 : 421-431.

Pagezy H. 1984 - Seasonal hunger as experienced by the Oto and the Twa women of a Ntomba village (lake Tumba, Zaïre). Ecol. Food Nutr., 15 : 13-27.

Pagezy H. 1985a - The food system of the Ntomba of lake Tumba, Zaïre. In Pottier J. (Ed.), Food systems in central and southern Africa, S.O.A.S, London : 61-79.

Pagezy H. 1985b - Système alimentaire et système économique des Ntomba. Analyse de la situation actuelle des villageois oto et de leurs pygmées twa (lac Tumba, Zaïre). Écologie Humaine, Aix en Provence, III (3-4) : 43-49.

Pagezy H. 1986 - Production et consommation alimentaires dans les campements de pêche de Nzalekenga (lac Tumba, Zaïre). Bull. Mém. Soc. Anthrop. Paris, T. 3, série XIV, n² : 87-104.

Pagezy H. 1988a - Contraintes nutritionnelles en milieu forestier équatorial liées à la saisonnalité et la reproduction: réponses biologiques et stratégies de subsistance chez les ba-Oto et les ba-Twa du village de Nzalekenga (lac Tumba, Zaïre). Thèse de doctorat d'État es Sciences, Université d'Aix-Marseille III, $489 \mathrm{p}$.

Pagezy H. 1988b - Coping with uncertainty in food supply among the Oto and the Twa in the equatorial forest near Lake Tumba, Zaïre. In Garine I. de \& Harrison G.A. (Ed.) Coping with uncertainty in food supply. Oxford University Press : 175-209.

Pagezy H. 1992 - Chasse et pêche dans l'alimentation des Nromba du Zaïre. Bull. et Mém. de la Soc. d'Anthropologie de Paris, 3-4 :175-189.

Pagezy H. 1993 - The importance of natural resources in the diet of the young child in a flooded tropical forest in Zaïre. In Hladik C.M., Hladik A., Linares O.F., Semple A. \& Hadley M. (Ed.) Tropical forests, people and food. Man and biosphere series $n^{\circ} 13$, UNESCO/Parthenon Publishing Group : 365-380.

Pagezy H. 1995 - De l'adaptation nutritionnelle à la malnutrition. In Devisch R., De Boeck F. \& Jonckers D., Alimentations, traditions et développements en Afrique intertropicale. Paris : L'Harmattan : 272-303.

Pagezy H. 1996 - L'obésité culturelle : un artefact dans la croissance des jeunes femmes en Afrique Centrale. Cahiers d'Anthropologie et de Biométrie Humaine, XIV, n 1-2 : 113-117. 
Pagezy H. 2000 - Les campements de pêche chez les Ntomba du lac Tumba (RDC, Zaïre). In Brun B., Dufour A.H., Picon B. \& Ribéreau-Gayon M.D. (Ed.) Cabanes, cabanons et campements, Travaux de la Société d'Écologie Humaine, Éditions du Bergier : 183-192.

Pagezy H. 2004 - Gibiers, poissons ou chenilles ? Comment les Ntomba du Congo (ex Zaïre) satisfont-ils en toute saison leurs besoins en protéines et leurs normes culturelles. In Aubaile F., Bernard M. \& Pasquet P. (Ed.) La viande, un aliment, des symboles. Édisud, Collection Écologie Humaine : 191-204.

Pagezy H. 2006a - Le contexte magico-religieux de la pêche au lac Tumba : entre le "normal" et l'insolite, Journal des Africanistes 76 (2) : 44-62.

Pagezy H. 2006b - Alimentation et croissance : faut-il condamner les interdits alimentaires? Antropo, 11 : 119-127. www.didac.ehu.es/antropo,

Pagezy H. 2010 - Le partage alimentaire et ses bénéfices réels ou perçus ; quelques exemples pris dans différents contextes. Communication au colloque « Partager la nourriture », Lasseube, 30 mars-2 avril 2011, (sous presse).

Pagezy H. \& Hauspie R. 1985 - Seasonal variation in the growth rate of weight in African babies, aged 0 to 4 years. Ecol. Food Nutr., vol. $18: 29-41$.

Retel-Laurentin A. 1974 - Infécondité en Afrique Noire, maladies et conséquences sociales. Paris, Masson et Cie, $188 \mathrm{p}$.

Romaniuk A. 1967 - La fécondité des populations congolaises. IRES. Recherches africaines, T. IV, Mouton, Paris, La Haye, 348 p.

Sala-Diakanda M. 1980 - Approche ethnique des phénomènes démographiques : le cas du Zaïre. Recherches démographiques, Cahier $n^{\circ}$ 4, Cabay, Libraire-Editeur S.A., Louvain-La-Neuve, 433 p.

Scrimshaw N.S., Taylor C.E. \& Gordon J.E. 1971 - Interactions entre l'état nutritionnel et les infections. O.M.S., Genève, Série de Monographies n 57, 363 p.

Siccardi A.G., Peracino A., Marcovina S. \& Jayacar S.D. 1986 - Selected immunochemical and clinical laboratory data. In Cavalli-Sforza L.L. (Ed.) African Pygmies. Academic Press Inc., New York, Mondon, Montreal : 139-141.

Tardieu V. 1992 - Forêts des hommes, tropiques saccagés ou sauvés ? Paris, Robert Laffont : 189-216.

Van Everbroeck N. 1961 - Mbomb'Ipoku, le seigneur de l'abime. Musée Royal d'Afrique Centrale, n³, Tervuren, Belgique, $310 \mathrm{p}$.

Van Everbroeck N. 1974 - Ekond'e Mputela. Histoire, croyances, organisation clanique, politique, sociale et familiale des Ekonda et de leur Batoa. Musée Royal de l'Afrique Centrale, Tervuren, Belgique, Archives d'Anthropologie, $\mathrm{n}^{\circ} 21,306 \mathrm{p}$.

Walter T., Olivares M., Pizzaro F. \& Munoz C. 1997 - Iron, anemia and infection, Nutrition reviews, 55 (4) : 111-124.

\section{ANNEXES}

Tableau 5 : Examens médicaux effectués par le Dr D. Barbier (Institut Pasteur, IPOM) en juillet 1979 et 1980 


\begin{tabular}{|c|c|c|c|c|c|c|c|}
\hline & \multirow{3}{*}{\begin{tabular}{c|}
$\begin{array}{c}\text { Enfants oto } \\
5-19 \text { ans }\end{array}$ \\
$\begin{array}{c}N=56 \\
32 \%\end{array}$ \\
\end{tabular}} & \multirow{3}{*}{$\begin{array}{c}\text { baOto } \\
20-39 \text { ans } \\
N=39 \\
49 \% \\
\end{array}$} & \multirow{3}{*}{$\begin{array}{c}\text { baOto } \\
40 \text { ans }+ \\
N=40 \\
33 \% \\
\end{array}$} & \multirow{3}{*}{$\begin{array}{c}\begin{array}{c}\text { Enfants twa } \\
5-19 \text { ans }\end{array} \\
N=17 \\
24 \% \\
\end{array}$} & \multirow{3}{*}{$\begin{array}{c}\text { baTwa } \\
20-39 \text { ans } \\
N=11 \\
18 \% \\
\end{array}$} & \multirow{3}{*}{$\begin{array}{r}\text { baTwa } \\
40 \text { ans + } \\
\begin{array}{r}N=15 \\
53 \%\end{array}\end{array}$} \\
\hline & & & & & & & \\
\hline \multirow{2}{*}{ Hépatomégalie \% } & Hommes & & & & & & \\
\hline & Femmes & $\begin{array}{r}N=46 \\
24 \% \\
\end{array}$ & $\begin{array}{r}N=41 \\
17 \% \\
\end{array}$ & $\begin{array}{r}N=47 \\
53 \% \\
\end{array}$ & $\begin{array}{r}N=19 \\
32 \% \\
\end{array}$ & $\begin{array}{r}N=21 \\
29 \% \\
\end{array}$ & $\begin{array}{r}N=18 \\
50 \%\end{array}$ \\
\hline \multirow{2}{*}{ Splénomégalie \% } & Hommes & $\begin{array}{r}N=56 \\
52 \%\end{array}$ & $\begin{array}{r}N=39 \\
10 \%\end{array}$ & $\begin{array}{r}N=40 \\
15 \%\end{array}$ & $\begin{array}{l}N=17 \\
71 \%\end{array}$ & $\begin{array}{l}N=11 \\
55 \%\end{array}$ & $\begin{array}{l}N=15 \\
40 \%\end{array}$ \\
\hline & Femmes & $\begin{array}{r}N=46 \\
54 \%\end{array}$ & $\begin{array}{r}N=42 \\
21 \%\end{array}$ & $\begin{array}{r}N=49 \\
29 \%\end{array}$ & $\begin{array}{r}N=19 \\
53 \%\end{array}$ & $\begin{array}{r}N=21 \\
48 \%\end{array}$ & $\begin{array}{r}N=19 \\
63 \%\end{array}$ \\
\hline & & \multicolumn{2}{|l|}{$\begin{aligned} & \text { Oto } \\
< & 20 \text { ans }\end{aligned}$} & $\begin{array}{c}\text { Oto } \\
>20 \text { ans }\end{array}$ & \multicolumn{2}{|c|}{$\begin{aligned} & \text { Twa } \\
< & 20 \text { ans }\end{aligned}$} & $\begin{array}{c}\text { Twa } \\
>20 \text { ans }\end{array}$ \\
\hline \multirow{2}{*}{\begin{tabular}{|c|} 
Thyroìde $\%$ \\
(Prévalence du goitre \\
codé de 1 à $2 ; 3$ sujets $>3$ \\
après 20 ans) \\
\end{tabular}} & Hommes & \multicolumn{2}{|l|}{$\begin{array}{r}N=65 \\
4,6 \%\end{array}$} & $\begin{array}{r}N=79 \\
1,3 \% \\
\end{array}$ & \multicolumn{2}{|l|}{$\begin{array}{r}N=24 \\
0 \%\end{array}$} & $\begin{array}{l}N=26 \\
3,8 \%\end{array}$ \\
\hline & Femmes & $\begin{array}{r}N=60 \\
3,3 \%\end{array}$ & & $\begin{array}{r}N=89 \\
4,5 \%\end{array}$ & \multicolumn{2}{|l|}{$\begin{array}{r}N=22 \\
0 \%\end{array}$} & $\begin{array}{l}N=42 \\
14,3 \%\end{array}$ \\
\hline & & \multicolumn{3}{|c|}{ Systolique $>150$} & \multicolumn{3}{|c|}{ Diastolique $>90$} \\
\hline & & baOto & & baTwa & baOto & & baTwa \\
\hline \multirow{3}{*}{$\begin{array}{c}\text { Hypertension artérielle } \\
\%\end{array}$} & Hommes & $\begin{array}{l}N=92 \\
5,4 \%\end{array}$ & & $\begin{array}{r}N=25 \\
0 \%\end{array}$ & $\begin{array}{l}N=92 \\
16,3 \%\end{array}$ & & $\begin{array}{r}N=25 \\
4,0 \%\end{array}$ \\
\hline & Femmes & $\begin{array}{r}N=101 \\
5,9 \% \\
\end{array}$ & & $\begin{array}{l}N=39 \\
2,6 \%\end{array}$ & $\begin{array}{r}N=101 \\
12,9 \% \\
\end{array}$ & & $\begin{array}{r}N=39 \\
2,6 \%\end{array}$ \\
\hline & $\begin{array}{l}\text { Réserve de sel } \\
\mathrm{N} \text { foyers } \\
\mathrm{N} \text { Personnes } \\
\mathrm{g} / \text { foyer/jour } \\
\mathrm{g} / \text { pers/j }\end{array}$ & $\begin{array}{r}0-340 \mathrm{~g} \\
29 \\
135 \\
17 \\
3,9 \mathrm{~g}\end{array}$ & & $\begin{array}{r}0-110 \mathrm{~g} \\
13 \\
86 \\
9 \\
9 \\
1,4 \mathrm{~g}\end{array}$ & & & \\
\hline
\end{tabular}

Prévalences de l'hépatomégalie (codée de 0 à 2), de la splénomégalie (codée de 0 à $5 ; 1$ seul sujet > 3), du développement de la thyroïde (codé de 0 à $4 ; 3$ sujets $>1$ ), de l'hypertension artérielle systolique et diastolique

D’après Pagezy 1988a

Tableau 6a : Correspondance entre densité d'œufs (D) estimée par le Dr D. Barbier et la charge parasitaire en nombre d'œufs par gramme de selles, recueillies sur solution de M.I.F, d'après comptage dans $15 \mathrm{mg}$ de selles suivant la méthode de Kato

\begin{tabular}{|c|c|c|c||c|c|c||c|c|c|}
\cline { 2 - 9 } \multicolumn{1}{c|}{} & \multicolumn{4}{c|}{ ASCARIS } & \multicolumn{3}{c||}{ ANKYLOSTOMES } & \multicolumn{3}{c|}{ TRICHOCÉPHALES } \\
\hline Densité d'œufs & $\mathrm{N}$ & $\mathrm{X}+\mathrm{sX}$ & Charge/g & $\mathrm{N}$ & $\mathrm{X}+\mathrm{sx}$ & Charge/g & $\mathrm{N}$ & $\mathrm{X}+\mathrm{sX}$ & Nbre/g \\
\hline 1 & 19 & $34+11$ & $2266 / \mathrm{g}$ & 33 & $24+9$ & $1600 / \mathrm{g}$ & 27 & $13+5$ & $867 / \mathrm{g}$ \\
\hline 2 & 17 & $114+24$ & $7600 / \mathrm{g}$ & 39 & $31+7$ & $2067 / \mathrm{g}$ & 22 & $23+11$ & $1533 / \mathrm{g}$ \\
\hline 3 & 19 & $301+59$ & $20066 / \mathrm{g}$ & 17 & $61+22$ & $4067 / \mathrm{g}$ & & & \\
\hline
\end{tabular}

D’après D. Barbier 1979-80 (Pagezy 1988a)

Tableau $6 \mathrm{~b}$ : Ascaris

\begin{tabular}{|c|c|c|c|c|c|c|c|c|c|c|c|}
\hline ÂGE années & $<2$ & $2-9$ & $10-19$ & $20-39$ & $40+$ & ÂGE années & $<2$ & $2-9$ & $10-19$ & $20-39$ & $40+$ \\
\hline $\begin{array}{l}\text { Hommes oto } \\
\mathrm{N} \\
\text { Prévalence \% } \\
\text { Densité }\end{array}$ & $\begin{array}{l}18 \\
33 \\
0,77\end{array}$ & $\begin{array}{l}72 \\
56 \\
1,21\end{array}$ & $\begin{array}{l}59 \\
73 \\
1,75\end{array}$ & \begin{tabular}{|l}
65 \\
62 \\
1,23
\end{tabular} & $\begin{array}{l}55 \\
40 \\
0,73\end{array}$ & \begin{tabular}{|l|} 
Hommes twa \\
$\mathrm{N}$ \\
Prévalence \% \\
Densité
\end{tabular} & 4 & \begin{tabular}{|l}
26 \\
73 \\
1,73
\end{tabular} & $\begin{array}{l}12 \\
75 \\
4,67\end{array}$ & \begin{tabular}{|l}
16 \\
69 \\
1,56
\end{tabular} & $\begin{array}{c}14 \\
79 \\
1,64\end{array}$ \\
\hline $\begin{array}{l}\text { Femmes oto } \\
\mathrm{N} \\
\text { Prévalence \% } \\
\text { Densité }\end{array}$ & $\begin{array}{l}16 \\
38 \\
0,75\end{array}$ & $\begin{array}{l}70 \\
60 \\
1,17\end{array}$ & \begin{tabular}{|l}
61 \\
70 \\
1,56
\end{tabular} & $\begin{array}{l}64 \\
66 \\
1,31\end{array}$ & $\begin{array}{l}62 \\
48 \\
1,05\end{array}$ & \begin{tabular}{|l|} 
Femmes twa \\
$N$ \\
Prévalence \% \\
Densité
\end{tabular} & $\begin{array}{l}12 \\
67 \\
1,41\end{array}$ & $\begin{array}{l}31 \\
71 \\
1,68\end{array}$ & $\begin{array}{l}15 \\
80 \\
1,73\end{array}$ & $\begin{array}{l}33 \\
82 \\
1,88\end{array}$ & $\begin{array}{l}28 \\
79 \\
2,04\end{array}$ \\
\hline
\end{tabular}

Prévalence et charge parasitaire moyenne (D codé de 0 à 4) en ascaris en fonction de l'âge à Nzalekenga

D’après D. Barbier, 1979-80 (Pagezy 1988a)

Tableau $6 \mathrm{c}$ : Ankylostomes 


\begin{tabular}{|c|c|c|c|c|c|c|c|c|c|c|c|c|c|}
\hline ÂGE (années) & $<2$ & $2-4$ & $5-9$ & $10-19$ & $20-39$ & $40+$ & ÂGE (années) & $<2$ & $2-4$ & $5-9$ & $10-19$ & $20-39$ & $40+$ \\
\hline $\begin{array}{l}\text { Hommes oto } \\
\mathrm{N} \\
\text { Prévalence \% } \\
\text { Densité } \\
\end{array}$ & $\begin{array}{l}18 \\
28 \\
0,33 \\
\end{array}$ & $\begin{array}{l}31 \\
71 \\
1,42 \\
\end{array}$ & $\begin{array}{l}41 \\
88 \\
1,98\end{array}$ & $\begin{array}{l}59 \\
81 \\
1,54\end{array}$ & \begin{tabular}{|l|}
65 \\
72 \\
1,48 \\
\end{tabular} & $\begin{array}{c}55 \\
75 \\
1,47 \\
\end{array}$ & $\begin{array}{l}\text { Hommes twa } \\
\mathrm{N} \\
\text { Prévalence \% } \\
\text { Densité }\end{array}$ & 4 & $\begin{array}{c}16 \\
69 \\
1,68\end{array}$ & $\begin{array}{l}10 \\
90 \\
1,90 \\
\end{array}$ & $\begin{array}{l}12 \\
67 \\
1,25 \\
\end{array}$ & \begin{tabular}{|l|}
16 \\
69 \\
1,25 \\
\end{tabular} & $\begin{array}{c}14 \\
86 \\
1,71\end{array}$ \\
\hline $\begin{array}{l}\text { Femmes oto } \\
\text { N } \\
\text { Prévalence \% } \\
\text { Densité }\end{array}$ & $\begin{array}{l}31 \\
0,87\end{array}$ & $\begin{array}{c}33 \\
70 \\
1,33 \\
\end{array}$ & $\begin{array}{l}78 \\
1,22 \\
\end{array}$ & $\begin{array}{l}61 \\
77 \\
1,57 \\
\end{array}$ & \begin{tabular}{|l|}
84 \\
1,59 \\
\end{tabular} & $\begin{array}{l}62 \\
76 \\
1,65 \\
\end{array}$ & $\begin{array}{l}\mathrm{N} \\
\text { Prévalence \% } \\
\text { Densité }\end{array}$ & $\begin{array}{l}12 \\
27 \\
0,75 \\
\end{array}$ & $\begin{array}{l}12 \\
67 \\
1,50 \\
\end{array}$ & $\begin{array}{l}19 \\
68 \\
1,47 \\
\end{array}$ & $\begin{array}{c}15 \\
100 \\
1,93\end{array}$ & $\begin{array}{c}33 \\
79 \\
1,46 \\
\end{array}$ & $\begin{array}{c}28 \\
86 \\
1,79 \\
\end{array}$ \\
\hline
\end{tabular}

Prévalence et charge parasitaire moyenne (D codé de 0 à 4 ) en ankylostomes en fonction de l'âge à Nzalekenga

D’après D. Barbier, 1979-80 (Pagezy, 1988a)

Tableau $6 \mathrm{~d}$ : Trichocéphales

\begin{tabular}{|l|c|c|c|c|c||l|l|l|l|l|l|}
\hline ÂGE (années) & $<2$ & $2-9$ & $10-19$ & $20-39$ & $40+$ & ÂGE (années) & $<2$ & $2-9$ & $10-19$ & $20-39$ & $40+$ \\
\hline Hommes oto & & & & & & Hommes twa & & & & & \\
$\mathrm{N}$ & 18 & 72 & 59 & 65 & 55 & $\mathrm{~N}$ & 4 & 26 & 12 & 16 & 14 \\
Prévalence & 39 & 56 & 54 & 29 & 33 & Prévalence & & 85 & 75 & 75 & 71 \\
Densité & 0,50 & 0,65 & 0,88 & 0,40 & 047 & Densité & & 1,85 & 1,42 & 1,19 & 1,43 \\
\hline Femmes oto & & & & & & Femmes twa & & & & & \\
N & 16 & 70 & 61 & 61 & 62 & N & 12 & 31 & 15 & 33 & 28 \\
Prévalence & 44 & 39 & 26 & 38 & 40 & Prévalence & 75 & 74 & 60 & 70 & 79 \\
Densité & 0,50 & 0,69 & 0,4 & 0,50 & 0,60 & Densité & 1,08 & 1,48 & 0,7 & 1,42 & 1,29 \\
\hline
\end{tabular}

Prévalence et charge parasitaire moyenne (D codé de 0 à 4 ) en trichocéphales en fonction de l'âge à Nzalekenga

D’après D. Barbier, 1979-80 (Pagezy, 1988a)

Tableau 7a: Filaires

\begin{tabular}{|c|c|c|c|c|c|c|c|c|c|c|c|}
\hline ÂGE années & $2-4$ & $5-9$ & 10-19 & 20-39 & $40-59$ & ÂGE années & $2-4$ & $5-9$ & $10-9$ & $20-39$ & $40-59$ \\
\hline $\begin{array}{l}\text { Hommes oto } \\
\mathrm{N} \\
\text { Moyenne } \\
\text { Maxi }\end{array}$ & $\begin{array}{r}22 \\
6 \\
109\end{array}$ & $\begin{array}{r}38 \\
12 \\
180\end{array}$ & $\begin{array}{r}58 \\
78 \\
568\end{array}$ & $\begin{array}{r}54 \\
255 \\
6403\end{array}$ & $\begin{array}{r}32 \\
468 \\
2000\end{array}$ & $\begin{array}{l}\text { Hommes twa } \\
\mathrm{N} \\
\text { Moyenne } \\
\text { Maxi }\end{array}$ & $\begin{array}{r}12 \\
5 \\
23\end{array}$ & $\begin{array}{r}9 \\
19 \\
59\end{array}$ & $\begin{array}{r}10 \\
110 \\
559\end{array}$ & $\begin{array}{r}13 \\
277 \\
930\end{array}$ & $\begin{array}{r}10 \\
457 \\
1000\end{array}$ \\
\hline $\begin{array}{l}\text { Femmes oto } \\
\mathrm{N} \\
\text { Moyenne } \\
\text { Maximum }\end{array}$ & $\begin{array}{r}19 \\
3 \\
53\end{array}$ & $\begin{array}{r}24 \\
22 \\
385\end{array}$ & $\begin{array}{r}47 \\
35 \\
405\end{array}$ & $\begin{array}{r}47 \\
51 \\
650\end{array}$ & $\begin{array}{r}31 \\
230 \\
3000\end{array}$ & $\begin{array}{l}\text { Femmes twa } \\
\mathrm{N} \\
\text { Moyenne } \\
\text { Maxi }\end{array}$ & $\begin{array}{r}19 \\
5 \\
84\end{array}$ & $\begin{array}{r}13 \\
27 \\
125\end{array}$ & $\begin{array}{r}10 \\
92 \\
445\end{array}$ & $\begin{array}{r}26 \\
186 \\
820\end{array}$ & $\begin{array}{r}14 \\
312 \\
1000\end{array}$ \\
\hline
\end{tabular}

Charge parasitaire en filaire (Dipetalonema persistans) en fonction de l'âge dans $35 \mu$ lhelene pagezy2013-03-27T15:53:00 de sang (Hommes et Femmes Oto et Twa de Nzalekenga). La Loa n'a été trouvée que chez 9 sujets : 6 baOto et 3 baTwa, dont 5 hommes et 4 femmes (Pagezy, 1988a)

D. Barbier, nov.1979-janv.1980

Tableau $7 \mathrm{~b}$ : Éosinophilie (Normal < $5 \%$ )

\begin{tabular}{|c|c|c|c|c|c|c|c|c|}
\hline ÂGE années & $5-9$ & $10-19$ & $20-39$ & $40-59$ & ÂGE années & $10-19$ & $20-39$ & $40-59$ \\
\hline $\begin{array}{l}\text { Hommes oto } \\
\mathrm{N} \\
\text { Moyenne } \\
\text { Maxi absolu }\end{array}$ & $\begin{array}{c}6 \\
12 \% \\
20 \%\end{array}$ & $\begin{array}{l}27 \\
10 \% \\
52 \%\end{array}$ & $\begin{array}{l}45 \\
12 \% \\
42 \%\end{array}$ & $\begin{array}{l}32 \\
10 \% \\
46 \%\end{array}$ & $\begin{array}{l}\text { Hommes twa } \\
\mathrm{N} \\
\text { Moyenne } \\
\text { Maxi absolu }\end{array}$ & $\begin{array}{c}7 \\
7 \% \\
13 \%\end{array}$ & $\begin{array}{l}11 \\
12 \% \\
28 \%\end{array}$ & $\begin{array}{c}14 \\
8 \% \\
20 \%\end{array}$ \\
\hline $\begin{array}{l}\text { Femmes oto } \\
\mathrm{N} \\
\text { Moyenne } \\
\text { Maxi absolu }\end{array}$ & $\begin{array}{c}6 \\
9 \% \\
18 \%\end{array}$ & $\begin{array}{l}30 \\
12 \% \\
52 \%\end{array}$ & $\begin{array}{c}42 \\
8 \% \\
20 \%\end{array}$ & $\begin{array}{c}31 \\
8 \% \\
20 \%\end{array}$ & $\begin{array}{l}\text { Femmes twa } \\
\mathrm{N} \\
\text { Moyenne } \\
\text { Maxi absolu }\end{array}$ & $\begin{array}{c}8 \\
14 \% \\
37 \%\end{array}$ & $\begin{array}{c}22 \\
6 \% \\
26 \%\end{array}$ & $\begin{array}{c}15 \\
9 \% \\
24 \%\end{array}$ \\
\hline
\end{tabular}

Formule sanguine : taux de polynucléaires éosinophiles en fonction du sexe et de l'âge en nov-déc 1979

D’après Dr Cheblal, Hôpital Saint Pierre, Bruxelles (Pagezy 1988a).

Tableau 8a : Hémoglobine, anémie (hommes) 


\begin{tabular}{|c|c|c|c|c|c|c|c|c|c|c|c|}
\hline ÂGE années & $<5$ & $5-9$ & $10-19$ & $20-39$ & $40-59$ & ÂGE années & $<5$ & $5-9$ & $10-19$ & $20-39$ & $40-59$ \\
\hline $\begin{array}{l}\text { Hommes oto } \\
N\end{array}$ & 5 & 13 & 19 & 53 & 43 & $\begin{array}{l}\text { Hommes twa } \\
\mathrm{N}\end{array}$ & 3 & 2 & 4 & 15 & 14 \\
\hline $\mathrm{Hb}(\mathrm{g} / 100 \mathrm{ml})$ & 8,4 & 9,9 & 11,0 & 13,1 & 12,2 & $\mathrm{Hb}(\mathrm{g} / 100 \mathrm{ml})$ & 9,0 & 10,3 & 11,5 & 12,4 & 11,6 \\
\hline sx & & 0,4 & 0,3 & 0,2 & 0,2 & sx & & & & 0,4 & 0,3 \\
\hline ANEMIE & $5 / 5$ & $85 \%$ & $63 \%$ & $11 \%$ & $30 \%$ & ANEMIE & $3 / 3$ & $2 / 2$ & $3 / 3$ & $20 \%$ & $36 \%$ \\
\hline Minimum & 7,6 & 7,5 & 8,0 & 10,1 & 9,4 & Minimum & 8,3 & 9,5 & 10,3 & 9,5 & 9,2 \\
\hline Maximum & 8,9 & 12,3 & 14,4 & 16,2 & 15,0 & Maximum & 9,8 & 11,1 & 13,6 & 15,0 & 13,2 \\
\hline
\end{tabular}

Taux d'hémoglobine sanguin $(\mathrm{g} / 100 \mathrm{ml})$ et prévalence de l'anémie en fonction de l'âge (Pagezy 1988a)

Références adultes : $\mathrm{Hb}<13 \mathrm{~g} / 100 \mathrm{ml}$; enfants : $\mathrm{Hb}<11 \mathrm{~g} / 100 \mathrm{ml}$, selon OMS, 1975

(Hercberg, S., Galan, P., 1985).

Mesures prises sur place au miniphotomètre (Compur) en décembre 1979 et janvier 1980 (fin de saison des pluies - début de saison sèche).

Analyse de variance entre castes ( $\mathrm{F}$ Welch $=22,17, \mathrm{P}<0,001$ )

Tableau $8 \mathrm{~b}$ : Hématocrite (hommes)

\begin{tabular}{|l|c|c|c|c|c||l|c|c|c|c|c|}
\hline ÂGE années & $<5$ & $5-9$ & $10-19$ & $20-39$ & $40-59$ & ÂGE années & $<5$ & $5-9$ & $10-19$ & $20-39$ & $40-59$ \\
\hline Hommes oto & & & & & & Hommes twa & & & & & \\
$\mathrm{N}$ & 5 & 13 & 19 & 53 & 43 & $\mathrm{~N}$ & 3 & 2 & 4 & 15 & 14 \\
$\mathrm{Hm} \%$ & 29,6 & 31,8 & 34,8 & 41,4 & 38,3 & Hm $(\%$ & 29,7 & 31,5 & 34,5 & 37,9 & 34,7 \\
$\mathrm{sx}$ & 0,8 & 0,8 & 0,8 & 0,5 & 0,8 & sx & & & 2,7 & 1,2 & 1,8 \\
Minimum & 27 & 27 & 21 & 29 & 28 & Minimum & 26 & 29 & 29 & 32 & 18 \\
Maximum & 32 & 36 & 42 & 47 & 46 & Maximum & 33 & 34 & 42 & 44 & 42 \\
\hline
\end{tabular}

Hématocrite (\%) des hommes Oto et Twa Ntomba en fonction de l'âge

Mesures faites sur place à la minicentrifugeuse Compur 1100, en décembre 1979 et janvier 1980 (fin de saison des pluies-début de saison sèche). Analyse de variance entre castes ( $F$ Welch $=14,43, \mathrm{P}<0,001$ )

(Pagezy 1988a)

Tableau 8c : Hémoglobine, anémie (femmes)

\begin{tabular}{|l|c|c|c|c|c||l|l|l|c|c|c|}
\hline ÂGE années & $<5$ & $5-9$ & $10-19$ & $20-39$ & $40-59$ & ÂGE années & $<5$ & $5-9$ & $10-19$ & $20-39$ & $40-59$ \\
\hline Femmes oto & & & & & & Femmes twa & & & & & \\
$\mathrm{N}$ & 8 & 7 & 30 & 57 & 45 & $\mathrm{~N}$ & 1 & 3 & 12 & 25 & 24 \\
$\mathrm{Hb}(\mathrm{g} / 100 \mathrm{ml})$ & 8,3 & 9,2 & 10,7 & 10,7 & 10,9 & $\mathrm{Hb}(\mathrm{g} / 100 \mathrm{ml})$ & & 8,7 & 10,6 & 10,5 & 10,8 \\
$\mathrm{Sx}$ & & 0,6 & 0,3 & 0,1 & 0,2 & sx & & 0,1 & 0,4 & 0,3 & 0,5 \\
$\mathrm{ANÉMIE}$ & $8 / 8$ & $6 / 7$ & $50 \%$ & $49 \%$ & $44 \%$ & ANÉMIE & & $3 / 3$ & $50 \%$ & $44 \%$ & $42 \%$ \\
Minimum & 6,5 & 7,2 & 6,5 & 8,01 & 8,5 & Minimum & & 8,6 & 8,3 & 6,8 & 5,0 \\
Maximum & 11,3 & 11,5 & 14,0 & 12,9 & 12,9 & Maximum & & 8,9 & 13,5 & 12,6 & 14,5 \\
\hline
\end{tabular}

Taux d'hémoglobine sanguin $(\mathrm{g} / 100 \mathrm{ml})$ et prévalence de l'anémie en fonction de l'âge Adultes : $\mathrm{Hb}<12 \mathrm{~g} / 100 \mathrm{ml}$; enfants : $\mathrm{Hb}<11 \mathrm{~g} / 100 \mathrm{ml}$, selon OMS, 1975 (Pagezy 1988a). Mesures prises sur place au miniphotomètre (Compur) en décembre 1979 et janvier 1980 (fin de saison des pluies - début de saison sèche). Analyse de variance entre castes $F$ Welch : $17,48, \mathrm{P}<0,0001$ )

(Pagezy 1988a)

Tableau 8d : Hématocrite (femmes)

\begin{tabular}{|l|c|c|c|c|c||l|l|l|l|l|l|}
\hline ÂGE années & $<5$ & $5-9$ & $10-19$ & $20-39$ & $40-59$ & ÂGE années & $<5$ & $5-9$ & $10-19$ & $20-39$ & $40-59$ \\
\hline Femmes oto & & & & & & Femmes twa & & & & & \\
$\mathrm{N}$ & 8 & 7 & 30 & 57 & 45 & $\mathrm{~N}$ & & 3 & 12 & 25 & 24 \\
$\mathrm{Hm} \%$ & 27,5 & 30,9 & 33,7 & 33,9 & 34,2 & $\mathrm{Hm} \%$ & & 30,0 & 33,5 & 32,8 & 33,2 \\
$\mathrm{Sx}$ & 2,5 & 1,6 & 0.8 & 0,5 & 0,7 & $\mathrm{sx}$ & 1 & & 1,4 & 1,1 & 1,5 \\
Minimum & 22 & 24 & 21 & 16 & 26 & Minimum & & 29 & 25 & 13 & 13 \\
Maximum & 36 & 36 & 42 & 47 & 40 & Maximum & & 31 & 42 & 39 & 41 \\
\hline
\end{tabular}

Hématocrite (\%) des femmes Oto et Twa Ntomba en fonction de l'âge (Pagezy 1988a). Mesures faites sur place à la minicentrifugeuse Compur 1100, en décembre 1979 et janvier 1980 (fin de saison des pluies-début de saison sèche). Analyse de variance entre castes ( $\mathrm{F}$ Welch $=3,01 \mathrm{P}<0,01$ ) 
(Pagezy 1988a)

Tableau 9a : Albumine sérique (hommes)

\begin{tabular}{|l|r|r|r|r||l|r|r|r|r|}
\hline \multicolumn{1}{|c|}{ ÂGE années } & $5-9$ & $10-19$ & $20-39$ & $40-59$ & \multicolumn{1}{|c|}{ ÂGE années } & $5-9$ & $10-19$ & $20-39$ & $40-59$ \\
\hline Hommes oto & & & & & Hommes twa & & & & \\
N & 5 & 49 & 53 & 44 & N & 0 & 11 & 17 & 17 \\
Albumine $(\mathrm{mg} / 100 \mathrm{ml})$ & 2793 & 2628 & 3061 & 2774 & Albumine $(\mathrm{mg} / 100 \mathrm{ml})$ & & 2697 & 2351 & 2310 \\
sX & 224 & 86 & 91 & 130 & sx & & 161 & 157 & 207 \\
Minimum & 1994 & 1205 & 1960 & 1174 & Minimum & & 1845 & 1859 & 1474 \\
Maximum & 3241 & 3970 & 5056 & 4772 & Maximum & & 3562 & 4319 & 4123 \\
\hline
\end{tabular}

Teneur plasmatique en albumine des hommes Ntomba Oto et twa en fonction de l'âge Analyse de variance entre castes : $\mathrm{F}$ Welch $=17,6(\mathrm{P}<0,001)$. Analyses effectuées à Bruxelles, au néphélomètre laser, service de pédiatrie de l'hôpital Saint Pierre, Bruxelles

(Pagezy 1988a)

Tableau 9b : Albumine sérique (femmes)

\begin{tabular}{|l|r|r|r|r||l|r|r|r|r|}
\hline \multicolumn{1}{|c|}{ ÂGE années } & $5-9$ & $10-19$ & $20-39$ & $40-59$ & ÂGE années & $5-9$ & $10-19$ & $20-39$ & $40-59$ \\
\hline Femmes oto & & & & & Femmes twa & & & & \\
N & 4 & 56 & 43 & N & 0 & 12 & 32 & 25 \\
Albumine $(\mathrm{mg} / 100 \mathrm{ml})$ & 2796 & 2699 & 2743 & 2615 & Albumine $(\mathrm{mg} / 100 \mathrm{ml})$ & & 2597 & 2822 & 2577 \\
Sx & & 85 & 77 & 138 & sx & & 172 & 201 & 115 \\
Minimum & 2066 & 1547 & 1282 & 1530 & Minimum & & 1900 & 1501 & 1390 \\
maximum & 4569 & 4590 & 4014 & 3510 & Maximum & & 4287 & 6358 & 3739 \\
\hline
\end{tabular}

Teneur plasmatique en albumine des femmes Ntomba Oto et twa en fonction de l'âge Analyse de variance entre castes (F Welch = 0,70; NS). Analyses effectuées à Bruxelles, au néphélomètre laser, service de pédiatrie de l'hôpital Saint Pierre, Bruxelles

(Pagezy 1988a)

Tableau 10a1 : IgG (hommes)

\begin{tabular}{|l|r|r|r|r||l|r|r|r|r|}
\hline \multicolumn{1}{|c|}{$\hat{\text { ÂGE années }}$} & $5-9$ & $10-19$ & $20-39$ & $40-59$ & ÂGE années & $5-9$ & $10-19$ & $20-39$ & $40-59$ \\
\hline Hommes oto & & & & & Hommes twa & & & & \\
N & 5 & 49 & 53 & 44 & N & 0 & 11 & 17 & 17 \\
IgG (mg/100 mI WHO) & 2149 & 2244 & 2228 & 2269 & IgG (mg/100 ml WHO) & & 2178 & 2366 & 2603 \\
sx & & 63 & 90 & 128 & sX & & 456 & 111 & 153 \\
Minimum & 1817 & 920 & 904 & 817 & Minimum & & 1139 & 1658 & 1573 \\
Maximum & 2603 & 3669 & 4092 & 3679 & Maximum & & 2975 & 3112 & 3558 \\
\hline
\end{tabular}

Teneur plasmatique en IgG des hommes Ntomba Oto et Twa en déc. 1979-janv. 1980 en fonction de l'âge

Analyse de variance entre castes, $\mathrm{F}$ Welch $=0,80$ (NS). Analyses effectuées à Bruxelles, au néphélomètre laser, service de pédiatrie de l'hôpital Saint Pierre, Bruxelles

(Pagezy 1988a)

Tableau 10a2 : IgG (femmes)

\begin{tabular}{|l|r|r|r|r||l|r|r|r|r|}
\hline \multicolumn{1}{|c|}{ ÂGE années } & $5-9$ & $10-19$ & $20-39$ & $40-59$ & ÂGE années & $5-9$ & $10-19$ & $20-39$ & $40-59$ \\
\hline Femmes oto & & & & & Femmes twa & & & & \\
N & 4 & 49 & 53 & 44 & N & 0 & 12 & 32 & 25 \\
IgG (mg/100 ml WHO) & 1844 & 2025 & 2010 & 2500 & IgG (mg/100 ml WHO) & & 2170 & 2404 & 2904 \\
sX & & 82 & 75 & 131 & sx & & 136 & 121 & 164 \\
Minimum & 1558 & 1045 & 926 & 1137 & Minimum & & 1500 & 1281 & 1875 \\
Maximum & 2370 & 3101 & 3580 & 4415 & Maximum & & 2879 & 4299 & 4699 \\
\hline
\end{tabular}

Teneur plasmatique en IgG des femmes Ntomba Oto et Twa en fonction de l'âge en déc. 1979-janv. 1980

F Welch entre castes $=6,53(\mathrm{P}<0,001)$. Analyses effectuées à $\mathrm{B}$ Bruxelles, service de pédiatrie de l'hôpital Saint Pierre

(Pagezy 1988a)

Tableau 10 b1 : IgM (hommes) 


\begin{tabular}{|l|r|r|r|r||l|r|r|r|r|}
\hline \multicolumn{1}{|c|}{ ÂGE années } & $5-9$ & $10-19$ & $20-39$ & $40-59$ & ÂGE années & $5-9$ & $10-19$ & $20-39$ & $40-59$ \\
\hline Hommes oto & & & & & Hommes twa & & & & \\
N & 5 & 49 & 53 & 44 & N & 0 & 11 & 17 & 17 \\
IgM (mg/100 $\mathrm{ml}$ WHO) & 130 & 193 & 324 & 398 & IgM (mg/100 mI WHO) & & 203 & 159 & 449 \\
SX & & 16 & 46 & 85 & Sx & & 15 & 69 & 115 \\
Minimum & 67 & 71 & 74 & 62 & Minimum & & 113 & 96 & 127 \\
Maximum & 168 & 723 & 1593 & 2117 & Maximum & & 266 & 1112 & 1403 \\
\hline
\end{tabular}

Teneur plasmatique en IgM des hommes Ntomba Oto et Twa en fonction de l'âge en déc. 1979-janv. 1980

Analyse de variance entre castes, $\mathrm{F}$ Welch $=4,40(\mathrm{P}<0,01)$. Analyses effectuées à Bruxelles, service de pédiatrie de l'hôpital Saint Pierre

(Pagezy 1988a)

Tableau 10b2 : IgM (femmes)

\begin{tabular}{|l|r|r|r|r||l|r|r|r|r|}
\hline \multicolumn{1}{|c|}{ ÂGE années } & $5-9$ & $10-19$ & $20-39$ & $40-59$ & ÂGE années & $5-9$ & $10-19$ & $20-39$ & $40-59$ \\
\hline Femmes oto & & & & & Femmes twa & & & & \\
N & 4 & 43 & 56 & 43 & N & 0 & 12 & 32 & 25 \\
IgM (mg/100 ml WHO) & 108 & 176 & 579 & 316 & IgM (mg/100 ml WHO) & & 260 & 309 & 469 \\
sX & 14 & 11 & 37 & 41 & sx & & 50 & 42 & 103 \\
Minimum & 81 & 69 & 60 & 121 & Minimum & & 71 & 60 & 129 \\
Maximum & 147 & 430 & 1448 & 1312 & Maximum & & 554 & 1290 & 1858 \\
\hline
\end{tabular}

Teneur plasmatique en IgM des femmes Ntomba Oto et twa en fonction de l'âge en déc. 1979-janv. 1980

$\mathrm{F}$ Welch = 7,46 $(\mathrm{P}<0,001)$. Analyses effectuées à Bruxelles, service de pédiatrie de l'hôpital Saint Pierre

(Pagezy 1988a)

Tableau 11 : Anthropométrie saisonnière $(\mathrm{x}+\mathrm{sx})$ et mode de vie

\begin{tabular}{|c|c|c|c|c|c|c|}
\hline & & \multirow{2}{*}{$\begin{array}{c}\begin{array}{c}\text { Pêcheurs } \\
\text { permanents }\end{array} \\
\mathrm{N}=17\end{array}$} & \multirow{2}{*}{$\begin{array}{c}\begin{array}{c}\text { Pêcheurs } \\
\text { saisonniers }\end{array} \\
\qquad N=27\end{array}$} & \multicolumn{2}{|c|}{$\begin{array}{c}\text { Villageois } \\
\text { Adultes Âgés } \\
<50 \text { ans }>50 \text { ans }\end{array}$} & \multirow{2}{*}{$\begin{array}{c}\text { Enseignants } \\
\qquad N=12\end{array}$} \\
\hline & & & & $N=18$ & $N=19$ & \\
\hline $\begin{array}{l}\text { Stature } \\
(\mathrm{cm})\end{array}$ & $\begin{array}{l}x \\
\text { sx }\end{array}$ & $\begin{array}{c}171,2 \\
1,6\end{array}$ & $\begin{array}{c}167,3 \\
1,2\end{array}$ & $\begin{array}{c}170,8 \\
1,4\end{array}$ & $\begin{array}{c}165,7 \\
1,5\end{array}$ & $\begin{array}{c}169,9 \\
1,5\end{array}$ \\
\hline Poids (kg) & $\begin{array}{l}s s \\
s p \\
s x \\
P\end{array}$ & $\begin{array}{c}61,85 \\
61,90 \\
1,8 \\
\text { NS } \\
\end{array}$ & $\begin{array}{c}56,79 \\
54,95 \\
1,1 \\
c \\
\end{array}$ & $\begin{array}{c}56,49 \\
55,98 \\
1,9 \\
\text { NS }\end{array}$ & $\begin{array}{c}54,90 \\
53,44 \\
1,7 \\
\text { b }\end{array}$ & $\begin{array}{c}59,22 \\
58,20 \\
2,1 \\
a \\
\end{array}$ \\
\hline Quételet $\mathrm{Kg} / \mathrm{m}^{2}$ & $\begin{array}{l}s s \\
s p \\
\text { sx } \\
P\end{array}$ & $\begin{array}{c}21,12 \\
21,10 \\
0,45 \\
\text { NS }\end{array}$ & $\begin{array}{c}20,29 \\
19,65 \\
0,34 \\
c\end{array}$ & $\begin{array}{c}19,33 \\
19,19 \\
0,52 \\
\text { NS }\end{array}$ & $\begin{array}{c}20,00 \\
19,45 \\
0,47 \\
b\end{array}$ & $\begin{array}{c}20,51 \\
20,16 \\
0,71 \\
a\end{array}$ \\
\hline $\begin{array}{l}\text { Circonférence maigre } \\
\text { du bras }(\mathrm{cm})\end{array}$ & $\begin{array}{l}\text { ss } \\
\text { sp } \\
\text { sx } \\
P\end{array}$ & $\begin{array}{c}26,65 \\
26,78 \\
0,5 \\
\text { NS }\end{array}$ & $\begin{array}{c}25,58 \\
25,06 \\
0,4 \\
a\end{array}$ & $\begin{array}{c}25,26 \\
25,05 \\
0,5 \\
\text { NS }\end{array}$ & $\begin{array}{c}25,09 \\
24,61 \\
0,5 \\
a\end{array}$ & $\begin{array}{c}25,43 \\
25,08 \\
0,6 \\
\text { NS }\end{array}$ \\
\hline $\begin{array}{l}\text { Pli tric+bic. } \\
0,1 \mathrm{~mm}\end{array}$ & $\begin{array}{l}s s \\
s p \\
\text { sx } \\
P\end{array}$ & $\begin{array}{c}73,17 \\
71,77 \\
2,2 \\
\text { NS }\end{array}$ & $\begin{array}{c}77,00 \\
78,00 \\
2,8 \\
\text { NS }\end{array}$ & $\begin{array}{c}76,78 \\
71,28 \\
6,1 \\
\text { NS }\end{array}$ & $\begin{array}{c}79,53 \\
74,79 \\
4,2 \\
a\end{array}$ & $\begin{array}{c}90,58 \\
86,42 \\
7,3 \\
\text { NS }\end{array}$ \\
\hline $\begin{array}{c}\text { Pli sous scapulaire } \\
0,1 \mathrm{~mm}\end{array}$ & $\begin{array}{l}s s \\
s p \\
\text { sx } \\
P\end{array}$ & $\begin{array}{c}71,82 \\
71,06 \\
4,2 \\
\text { NS }\end{array}$ & $\begin{array}{c}80,70 \\
75,52 \\
3,3 \\
\text { NS }\end{array}$ & $\begin{array}{c}76,78 \\
71,28 \\
6,1 \\
\text { NS }\end{array}$ & $\begin{array}{c}79,53 \\
74,79 \\
4,2 \\
a\end{array}$ & $\begin{array}{c}90,58 \\
86,42 \\
7,3 \\
\text { NS }\end{array}$ \\
\hline
\end{tabular}

Hommes adultes ( $n$ = 93) de Nzalekenga mesurés en 1979, en fin de grande saison sèche (ss) et en fin de grande saison des pluies (sp). Test $t$ de Wilcoxon appliqué aux séries appariées ss et $\mathrm{sp}$ $\mathrm{a}: \mathrm{P}<0,05, \mathrm{~b}: \mathrm{P}<0,01, \mathrm{c}: \mathrm{P}<0,001$

Circonférence maigre du bras $=$ circonférence du bras $-($ pli tricipital + pli $x$ bicipital $) x p i$ / 2

(Pagezy, 1988a) 
Tableau 12 : Taux d'immunoglobulines $(\mathrm{x}+\underline{\mathrm{sx}})$ aux saisons sèche 1980 (ss) et pluvieuse 1979 (sp) en fonction du mode de vie

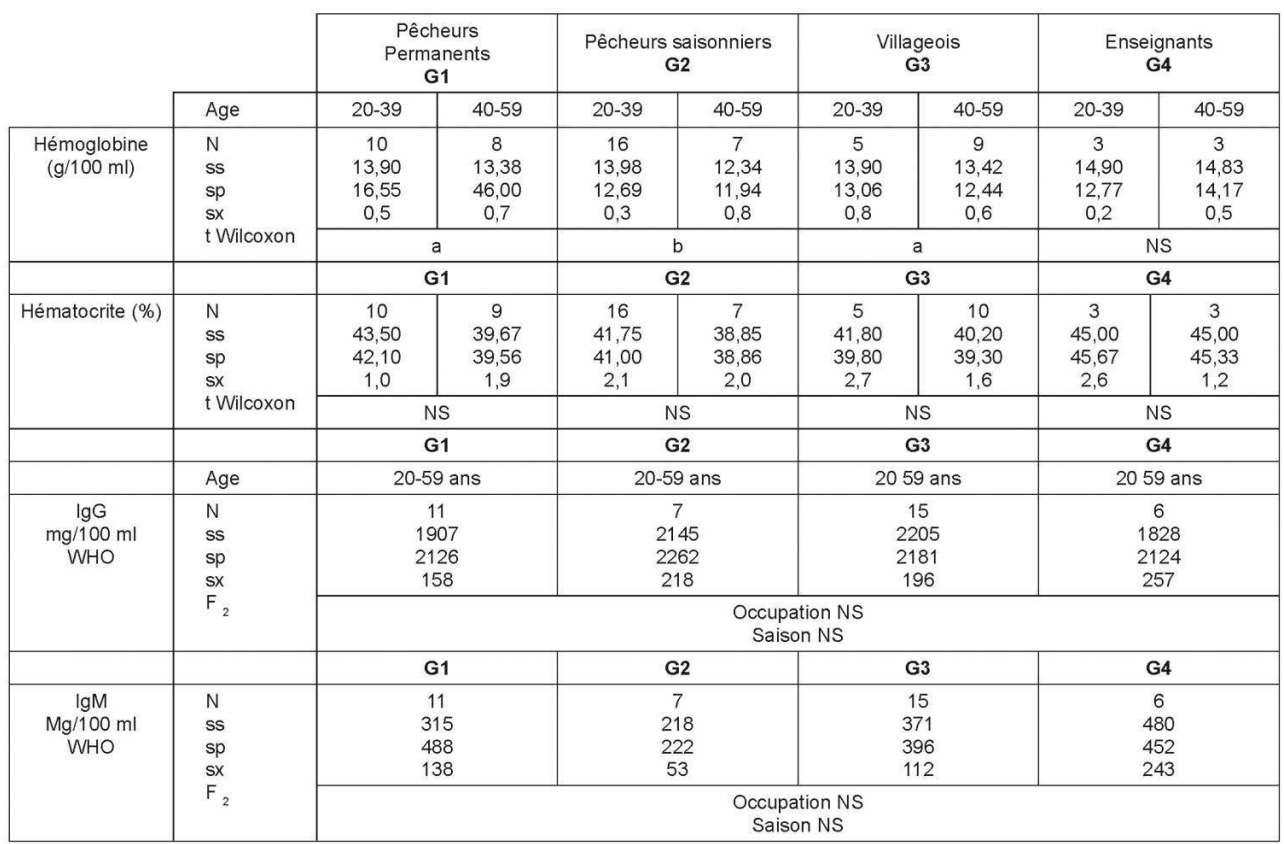

Hommes oto de Nzalekenga. Analyse de variance à deux facteurs

NS : non significative ; $\mathrm{a}: \mathrm{P}<0,05 ; \mathrm{b}: \mathrm{P}<0,01 ; \mathrm{c}: \mathrm{P}<0,001$

(Pagezy, 1988a)

\section{NOTES}

1. Cet article est le résultat de 60 mois de terrain effectués entre 1970 et 1991, depuis la station de recherche IRS-Mabali au bord du lac Tumba, puis dans le village de Nzalekenga. Les résultats présentés ci-dessous concernent essentiellement les missions effectuées au cours des années 1970 à 72, 1979-80 et 1989 à 91 . Il serait nécessaire de les actualiser pour éviter des conclusions obsolètes.

2. Dans la province de l'Équateur, les Mongo du Sud sont constitués principalement des ethnies Ntomba, Ekonda et Bolia (Van Everbroek 1961 et 1974). Celles-ci partagent une histoire commune ; elles reconnaissent le même chef coutumier, le nkumu ilanga qui réside chez les Bolia. Il est désigné par les puissances surnaturelles suite à un long parcours initiatique.

3. La forêt inondée est le biotope caractéristique de la Cuvette centrale, région commune aux deux Congo.

4. Bikoro, centre administratif et mission catholique, la mission protestante de Ntondo, et le Centre de Recherche Scientifique l'IRSAC-Mabali, abandonné après l'Indépendance avec le départ des chercheurs belges, sont situés sur la côte nord-orientale du lac Tumba; à proximité de Bikoro, la CEQUA, plantation d'hévéas, devenue Cultures Équatoriales, a suivi la vague de nationalisations commencées en 1973. À Lokanga, village du sud du lac, la plantation de café tenue par un Portugais a également été nationalisée. Toutes ces petites et moyennes sociétés ont réduit leurs activités.

5. C'est essentiellement pour cette raison et pour la difficulté à trouver à la fois des pièces de rechange pour les véhicules et des mécaniciens compétents, que, fin des années 80 , le transport fluvial par baleinières a remplacé le transport routier pour la circulation de passagers et de 
marchandises. Ces bateaux à fond plat, relient Kinshasa aux villages riverains du lac et même aux campements de pêche.

6. J'ai séparé par un point les préfixes démarquant le singulier du pluriel.

7. Dénommés aussi Grands Noirs, Villageois, Voisins (des Pygmées), ou Bantous. Cette dernière appellation est particulièrement erronée dans le cas des Ntomba qui parlent tous la même langue bantoue. Les baTwa préfèrent l'appellation de Pygmées qu'ils n'associent pas à l'attitude méprisante des Villageois lorsqu'ils les interpellent. Le discours de Mobutu à Bikoro qui, au début des années 70, a accordé aux Pygmées le statut égalitaire de "citoyen », y est certainement pour quelque chose. J'utiliserai les termes de moOto et moTwa (pluriel baOto et baTwa) en tant que substantifs, oto et twa en tant qu'adjectifs.

8. Les crânes et peaux de mammifères ont été rapportés au Muséum national d'Histoire naturelle (MNHN) de Paris. Les fruits, invertébrés et les poissons des marais ont été conservés dans l'alcool. Les déterminations de feuilles, fruits, amandes sauvages ont été faites par C. Evrard (laboratoire de botanique de l'UNAZA, ex Lovanium, RDC) et J. Raynal (laboratoire de phanérogamie du MNHN, Paris); les champignons et insectes (chenilles, larves) par R. Pujol (laboratoire d'ethnobotanique du MNHN, Paris) et G. Mathot (laboratoire de zoologie de l'UNAZA, RDC), les mammifères par J. Dorst et P. Dandelot (département des mammifères et oiseaux du MNHN). Plus généralement, je me suis servie des guides naturalistes sur les mammifères d'Afrique (Dorst et Dandelot 1972), les poissons du lac Tumba (Matthes 1964), les notes de botanique mongo (Hulstaert 1966) et le lexique Lontomba-Français de Mamet (1955).

9. J'ai organisé des enquêtes familiales quantitatives de consommation alimentaire durant 17 mois (février 1971-juin 1972) auprès de 40 familles oto et 40 familles twa de la route principale (groupement de Bonsende), 20 familles oto et 20 familles twa d'une route secondaire de forêt (groupement Besongo 1); en ce qui concerne les villages du lac (groupement Besongo 2), l'enquête mensuelle a été menée auprès de 20 familles de pêcheurs oto.

8. Les commerçants portugais tiennent le petit commerce dans les régions rurales. Basés à Mbandaka où se trouve leur magasin principal, ils parcourent deux fois par mois les routes de l'intérieur, magasin après magasin, jusqu'à leur plantation de café ou de cacao, où se trouve leur résidence secondaire et où vit leur épouse zaïroise. Expulsés au début des années 70 pour cause de nationalisation, le départ en masse de ces petits commerçants, très bien insérés dans la population, a accru l'isolement des régions les plus mal desservies, telle que la Cuvette centrale.

9. D'une façon générale, la spécialisation d'une caste ou d'un village ne concerne pas uniquement l'alimentation, mais aussi les autres activités de subsistance nécessitant la présence de ressources particulières. Par exemple, les panneaux de palmes pour couvrir les toits, les lits, les nattes ne sont fabriqués que dans certains villages, le plus souvent par les baTwa, tandis que l'on ne trouve des potières qu'au bord du lac, riche en argile (Pagezy 1985b).

10. Les ménages oto, ayant quatre plantations ou plus, en font une activité de rente. Les enseignants et les baOto polygames possèdent davantage de plantations, que ce soit de manioc ou de cultures de rente (café, cacao, palmier à huile).

11. En 1991, la majorité des baTwa n'étaient toujours pas devenus agriculteurs, malgré l'encouragement des missionnaires. À Nzalekenga, quelques hommes twa du quartier rebelle de Lokili, ayant défriché les terres données par le chef de terre, en ont été pour leur peine, leurs femmes ayant refusé de les cultiver, prétextant que le manioc préparé par les baOto était bien meilleur. Meilleur à penser certainement. Ce statut valorisé de la nourriture oto trouve son origine dans le mythe originel commun à ces deux groupes sympatriques (occupant la même aire géographique). Il est dit que l'ancêtre des baTwa, frère aîné de celui des baOto, a été banni par le patriarche, pour avoir caché son gibier en forêt au lieu de le lui remettre. Ses descendants ont été condamnés à vivre en forêt, sales comme des bêtes sauvages, et à ne pas cuisiner la nourriture convenablement. De nos jours, tous pensent que la nourriture pygmée est mal préparée et qu'elle a un mauvais goût, entretenant ainsi les différences de statut social et les interdits de 
consommation. Par ailleurs, le sarclage est l'activité qu'elles perçoivent comme la plus pénible, surpassant l'écopage en forêt inondée dont le coût physiologique (élévation du rythme cardiaque) est pourtant supérieur (Pagezy 1976).

12. En 1970, 1 zaïre =10 FF ou 2 US dollars; vingt ans plus tard (1990), il ne vaut plus qu'un centime de franc français. La dévaluation de la monnaie, de $100 \%$ par an après la zaïrisation, atteint $100 \%$ par mois en 1991 (Pagezy 1995).

13. J'ai pesé des tas d'aliments exposés pour la vente à différents moments de mon étude. Étonnamment, de façon intuitive, tous avaient pratiquement le même poids. La réponse aux nombreuses dévaluations de la monnaie vécue par la population a été la stabilité du prix de ces tas, compensée par un moindre nombre d'unités (fruits) ou une diminution du poids de l'aliment (pain de manioc), jouant le rôle de variable d'ajustement. Par exemple, entre 1970 et 1972, le prix du bâton de manioc cuit (e.nguele) est resté stable à 1 li.kuta, tandis que son poids est passé de $400 \mathrm{~g}$ à $250 \mathrm{~g}$. Ce n'est qu'ensuite que la dévaluation a touché le prix de vente, passant de $1 \mathrm{~K}$ à 10 K puis $100 \mathrm{~K}$ (1 zaïre) (Pagezy 1995).

14. En 1990, on ne trouve plus ni vélos ni colporteurs : le prix des vélos a décuplé pour une qualité incomparablement plus faible tandis que le pouvoir d'achat a fondu.

15. Les feuilles de manioc sont prélevées à l'extrémité des jeunes pieds de moins de trois mois, moins amères, en liaison avec leur moindre teneur en acide cyanhydrique.

16. Les examens médicaux de selles et la charge parasitaire ont été pratiqués sur place par le $\mathrm{Dr}$ Barbier. Les examens de sang (taux d'hémoglobine, hématocrite) ont aussi été réalisés par microméthode (miniphotomètre et minicentrifugeuse) sur place. Des taches de sang ont été conditionnées sur " papier-buvard » et les serum conservés au froid à la mission protestante de Ntondo jusqu'à notre retour en Europe. Les analyses ont été effectuées par néphélométrie par l'équipe de Pr H. L. Vis du service de pédiatrie de l'hôpital Saint Pierre à Bruxelles (Pagezy 1988a). Malgré le contexte difficile, la chaîne du froid a pu être respectée. Pour certaines mensurations, les femmes enceintes ont été exclues de l'échantillon.

17. Pour des raisons logistiques, seuls les baOto ont été testés aux deux saisons.

18. L'échantillon comportait 105 hommes oto et 29 twa âgés de 20 à 60 ans, 127 femmes oto (non enceintes) et 50 twa âgées de 15 à 60 ans.

19. Toute personne de passage doit recevoir l'hospitalité et être nourrie gracieusement par les pêcheurs, quelle que soit la durée de son séjour.

20. Au cours de mon séjour, j'ai eu l'occasion d'être témoin de la nostalgie des villageois à l'encontre des anciens colonisateurs et des bénéfices dont ils profitaient. La perception idéalisée de leur passé (encore proche) a été certainement influencée par l'histoire récente de leur pays marquée par le mobutisme.

21. Les réponses des baTwa à l'attitude méprisante de leurs nkolo consistaient en moqueries (imitations) et tricheries (camouflage du gibier, fuite en forêt).

\section{RÉSUMÉS}

L'article replace dans un contexte d'interdisciplinarité - écologie, anthropologie et biologie - les relations entre nourriture (espèces consommables) stratégies alimentaires, régime alimentaire et état nutritionnel des deux « castes » ntomba, les baOto agriculteurs-pêcheurs, pratiquant dans une moindre mesure la chasse et la cueillette, et les pygmées baTwa, descendants de chasseurscollecteurs, pratiquant dans une moindre mesure la pêche en forêt inondée. Suite à une longue 
période de contact, ces deux populations parlent la même langue et respectent les mêmes règles, à quelques nuances près. En 1970, début de ce terrain, la riche biodiversité est flagrante, protégée des transformations rapides par l'isolement.

L'article suit les différentes étapes de la construction du régime alimentaire, familial puis individuel, en se laissant guider par les spécificités des contextes environnemental, socio-culturel et socio-économique. La réalisation d'un régime permettant de faire face aux besoins biologiques et socio-culturel tire profit de la complémentarité des deux castes dans leurs stratégies alimentaires, alliances, vassalité, partages, échanges ayant pour finalité de ne pas mettre tous leurs œufs dans le même panier.

The article places the relationships between food, food strategies, diet and nutritional state back into an interdisciplinary context - ecological, anthropological and biological. It concerns both ntomba "castes" : the baOto, farmers and fishermen, who also hunt and harvest to a lesser extent; and the baTwa pygmies, descending from hunters-gatherers, who sometimes fish in flooded forest. After a long contact period, these two populations came to speak the same language and follow the same rules but for minor variations. In 1970, when this field experience began, there was an obvious biodiversity. Isolation protected it from quick transformation.

The article follows the various steps of setting up a family diet and then an individual diet. It is guided by the specificities of environmental, socio-cultural and socio-economical contexts.

The creation of a diet able to face biological as well as socio-cultural needs was a real challenge. Nevertheless, these two castes were compatible in their food strategies, alliances, vassalage, sharing and exchanges; which have been a true asset, allowing them not to put all their eggs in one basket.

INDEX

Index géographique : Afrique, République démocratique du Congo

Population Ntomba, Oto, Twa

Keywords : foodways, biological anthropology, fishermen, seasons, swamp forest

Mots-clés : alimentation, anthropobiologie, pêcheurs, forêt inondée, saisonnalité

\section{AUTEUR}

\section{HÉLÈNE PAGEZY}

Chercheure associée en Eco-anthropologie

UMR 7206, CNRS-Muséum

Muséum national d'Histoire naturelle

Paris 